\title{
Analytical fragility curves for masonry school building portfolios in Nepal
}

\author{
Nicola Giordano ${ }^{1}$ (D) . Flavia De Luca ${ }^{1}$ (D) - Anastasios Sextos ${ }^{1}$
}

Received: 4 October 2019 / Accepted: 20 October 2020 / Published online: 9 November 2020

(c) The Author(s) 2020

\begin{abstract}
Schools represent a reference point for communities in any part of the world. Therefore, their safety and resilience against natural catastrophes is of paramount importance. The recent 2015 Gorkha earthquake has unfortunately shown that Nepalese school buildings are highly vulnerable to seismic actions. Most of them are indeed constituted by low-quality unreinforced masonry (URM). The quantification of URM vulnerability is fundamental to estimate the risk associated to school building portfolios at territorial scale. This work discusses statistics available for Nepalese schools and then presents analytical fragility curves for three recurrent URM typologies covering more than 50\% of the school building stock. The methodology adopted to derive fragilities is spectral-based and accounts for outof-plane and in-plane damage potential in a single easy-to-use analytical framework. Interbuilding, intra-building and record-to-record variabilities are directly considered in the analysis. The obtained fragilities integrate the studies available for the region and can be used for pre-/post-earthquake risk assessment and prioritization of interventions at country level.
\end{abstract}

Keywords Nepal · Masonry · School building · Analytical fragility model · Vulnerability assessment $\cdot$ Out-of-plane damage $\cdot$ In-plane damage

\section{Introduction}

Nepal is among the poorest economies in the world (Muzzini and Aparicio 2013) and one of the less urbanized nations in South Asia with $80.3 \%$ of the population living in rural areas (United Nations Department of Economic and Social Affairs Population Division 2018). Non-engineered and unsafe constructions (mostly unreinforced masonry, URM) still constitute most of the building stock and, analogously, school facilities are characterized by a high level of seismic vulnerability. According to a 2014 report by the Asian Development Bank (ADB), $18 \%$ of the nation's schools need to be reconstructed, while $43 \%$ require major retrofitting interventions (Asian Development Bank 2014).

Nicola Giordano

nicola.giordano@bristol.ac.uk

1 Department of Civil Engineering, University of Bristol, Queens Building, University Walk, Bristol BS81TR, UK 
Unfortunately, the last catastrophic 2015 seismic event worsened this scenario. According to different post-earthquake reconnaissance reports (e.g., Aon Benfield 2015; Build Change 2015; Government of Nepal 2015; Paci-Green et al. 2015; EERI 2016), approximately 6000-8200 schools were destroyed by the 2015 sequence of events. Post-earthquake surveys carried out adopting the inspection form from the National Society for Earthquake Technology (NSET) resulted in 6000 school buildings tagged with a damage grade (DG) between 4 or 5 (i.e., very heavy damage or destruction) and 11,000 tagged with DG2 or DG3 (moderate or heavy damage). In the Sindhupalchowk district, 99\% of the classrooms exhibited a degree of seismic damage while, in Gorkha district, $85 \%$ of the classrooms collapsed. The Government of Nepal estimated the cost of damage and wider loss in the education sector to be of the order of \$300-\$400 million (Government of Nepal 2015).

In the face of this situation, governmental authorities and international non-governmental organizations (NGOs) have increased their effort in promoting coherent and coordinated actions on school safety (United Nations Office for Disaster Risk Reduction 2017). To achieve this goal, a systematic plan for assessing school facilities and prioritizing investments should be implemented by adopting state-of-the-art risk evaluation techniques (World Bank 2017). Therefore, the derivation of specific fragility curves for recurrent school building typologies is required (Gentile and Galasso 2019).

From a mathematical point of view, fragility curves express building physical damage in a probabilistic manner by describing the relationship between a relevant seismic intensity measure IM (e.g., peak ground acceleration, PGA) and the probability that a specific level of damage $\left(D S_{i}\right)$ is exceeded (D'Ayala et al. 2015):

$$
P\left(D S \geq D S_{i} \mid I M\right)
$$

Fragility curves are most commonly derived: (i) from expert opinions (expert/judgmental-based fragility curves); (ii) from statistical processing of post-quake reconnaissance data (empirical/observational fragility curves); or (iii) through analytical/numerical simulations (analytical fragility curves). Excluding the first approach, that could lack of scientific robustness (Aspinall 2010), the latter two techniques have been largely used in the last decades (e.g. Lagomarsino and Giovinazzi 2006; Jaiswal et al. 2011). In principle, observational fragilities should be considered the best option since they are based on damage evidence rather than simulations. However, their empirical nature is an intrinsic weakness (D'Ayala et al. 2015). Low quality of damage data and inaccuracy of earthquake shake-maps play an important role on the reliability of the results especially in data-scarce regions (McGowan et al. 2017).

Analytical fragilities are an alternative to overcome the limitations of empirical methods (Silva et al. 2019). Ideally, they should include all the sources of uncertainty e.g., geometry, material properties, static loads, ground motion, etc. (Calvi et al. 2006). Analytical fragilities based on numerical analyses, such as Finite Element Method (FEM) analyses, are generally time consuming as multiple FEM models need to be generated and analysed to include aleatory uncertainty. Therefore, several analytical fragility studies are based on simplified methods that require less computational effort.

In the Nepali context, some studies were carried out in recent years with the aim to develop observational and numerical fragility relationships. Guragain (2015) conducted a numerical study on four masonry types by adopting the Applied Element Method (AEM). Given the high computational cost of the AEM and the complexity of the calibration process (Malomo et al. 2018), fragility curves were derived considering eight models where random variation of geometry (e.g. walls thickness, interstory height, floor span, etc.) and 
mechanical properties (e.g., Young modulus, shear modulus, tensile strength, etc.) was not considered. Five scaled Ground Motions (GMs) were used to account for seismic input uncertainty. Chaulagain et al. (2016) derived fragility curves for general reinforced concrete buildings by adopting a numerical FEM approach. The same study includes some fragility curves for URM buildings whose source and typology is not reported. Gautam et al. (2018) developed observational fragility curves for three classes of Nepali residential buildings, namely, reinforced concrete (RC), brick masonry and stone masonry. This last work has the typical shortcomings of observational fragilities that use historical damage data (namely from 1934 Bihar-Nepal earthquake, 1980 Chainpur earthquake, 1988 Eastern Nepal earthquake, 2011 Eastern Nepal earthquake and 2015 Gorkha earthquake). More recently, the World Bank, within the Global Program for Safer Schools (ARUP 2015; World Bank 2017), has developed a global library of school infrastructure that includes information relevant to the Nepali context (World Bank 2019b). In particular, the database includes a set of index buildings for which fragility and vulnerability curves are reported. Additionally, thanks to a collaboration between the University of Bristol and the World Bank, a new empirical fragility model based on 18,000 school building damage data of the 2015 Gorkha earthquake has been recently produced (Giordano et al. 2020c). These works represent an important step towards the implementation of comprehensive seismic risk studies in Nepal (Robinson et al. 2018). However, our understanding of the vulnerability of the building stock in Nepal is still limited with respect to other regional contexts (YepesEstrada et al. 2016). A thorough risk/loss estimation should be performed with different fragility models to display a confidence interval on the results and to account for the epistemic uncertainties of the model (Hancilar et al. 2020). Additionally, referring to schools, a lack of tailored fragility curves could undermine the reliability of loss assessment and hinders the prioritization of building portfolios strengthening.

Given the widespread presence of masonry schools and their high vulnerability (Brando et al. 2017), this paper focuses on URM typologies and provides new fragility curves accounting for in-plane (IP) and out-of-plane (OOP) damage potential in a single easy-to-use analytical framework. Particularly, the OOP response is quantified with a recent model developed by the authors (Giordano et al 2020a). In details, Sect. 2 presents the characteristics of the URM school building stock by referring to data and information on the main structural typologies. Section 3 briefly reviews the existing methodologies for URM fragility assessment and presents the methodology adopted in this study. Section 4 presents the analysis of three recurrent masonry school typologies i.e. rubble stone in mud-mortar, brick in mud-mortar and brick in cement-mortar. Probabilistic input variables for the derivation of fragility curves are also discussed in the section. Lastly, new fragility curves for the considered URM typologies are presented and compared with existing studies relevant to the Nepali context (Sect. 5).

\section{URM school building stock}

According to previous studies (NSET 2000; ARUP 2015) there are mainly six school structural typologies in Nepal (Fig. 1). URM bearing wall buildings are generally made of: (i) field stones in mud-mortar [URM-SM] (Fig. 1a); (ii) fired bricks in mud-mortar [URM-BM] (Fig. 1b); (iii) fired bricks in cement-mortar [URM-BC], (Fig. 1c). Other frequent typologies are:

- Steel structures [S] with masonry infills mostly constructed under the World Bank "Earthquake Affected Areas Reconstruction and Rehabilitation" Project in the period 1992-1997, (Fig. 1d); 

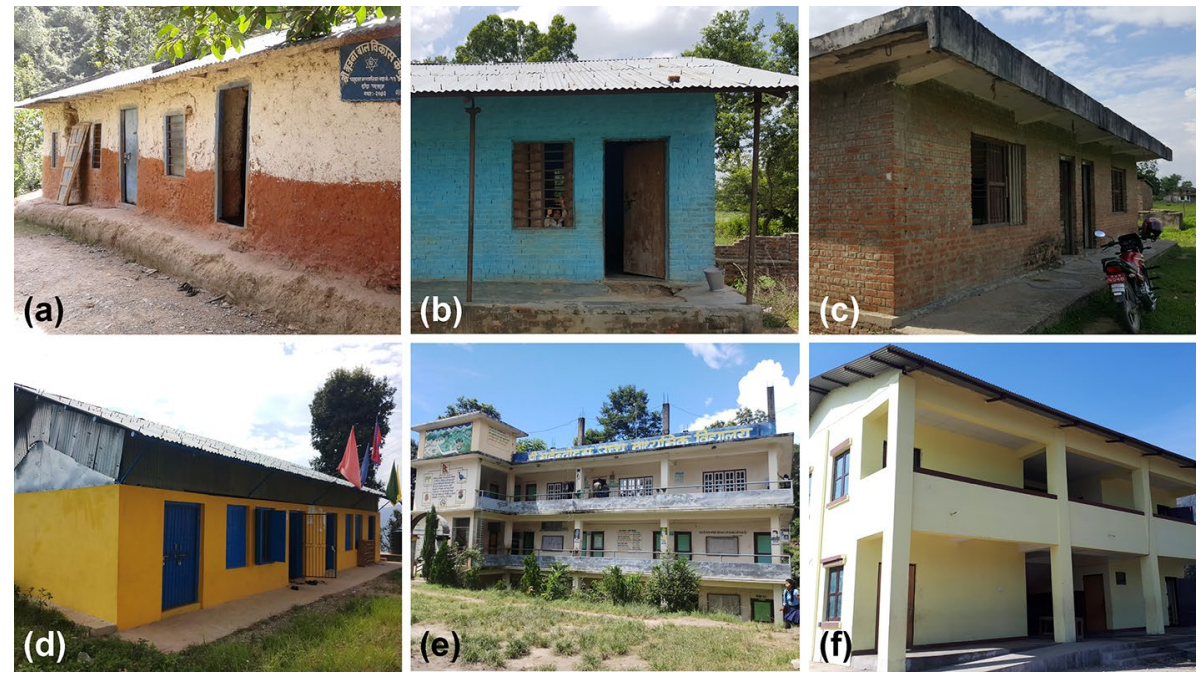

Fig. 1 School building typologies: a Stone-mud masonry [URM-SM], b brick-mud masonry [URM-BM], c brick-cement masonry [URM-BC], d metallic with masonry infill [S], e non-engineered RC [RC-N], f engineered RC [RC-E]. Source SAFER-App database, University of Bristol (Sextos and Mason 2018)

- RC structures that can be either non-engineered [RC-N] and engineered [RC-E] (Fig. 1e, f respectively).

Despite the large number of projects carried out on school facilities by governmental agencies and NGOs, a clear figure of the distribution of these structural typologies over the country is still lacking. ADB gives a rough indication of the school building types in different areas of the nation (Asian Development Bank 2014). In the plain area (terai), the RC framed structures are just $10 \%$ in favour of a more consistent presence of brick masonry (85\%). These percentage distributions consistently change in the hilly and mountain regions where most of the buildings (respectively 87\% and 97\%) are recognized as "other type" i.e., stone masonry, adobe, wooden or mixed-system structures. Similar data are reported in post-2015-earthquake survey reports where most of the school buildings in Nepal (89\%) are constituted by URM material (Paci-Green et al. 2015). Moreover, in mountain areas, because of the lack of construction materials such as fired bricks, cement and steel, $50 \%$ of these constructions are made of dry/mud-mortar rubble-stone masonry.

On the contrary, thanks to the vicinity to industrial activities, the distribution of school structural typologies in the Kathmandu Valley (KV) is different from the rest of the country. As reported by ADB (Asian Development Bank 2014), in the KV 30\% of the schools have a RC frame bearing system while $65 \%$ have brick masonry bearing walls. A more detailed estimation of the school structural taxonomy and distribution in the KV dates back to 2000 (NSET 2000). This work gives an indication of the construction techniques present in the region starting from a survey-based catalogue of 909 school buildings. According to the study, at the time of the survey there were 643 public schools in Bhaktapur, Lalitpur and Kathmandu districts with approximately 1 to 9 buildings for each institute. Figure 2 a reports the pie chart of the school dataset subdivided by structural typologies. It can be observed that about $65 \%$ of the school buildings are constituted by masonry material, split in 13\% [URM-SM] and 52\% [URM-BM/BC]. The second most recurrent school 
(a)

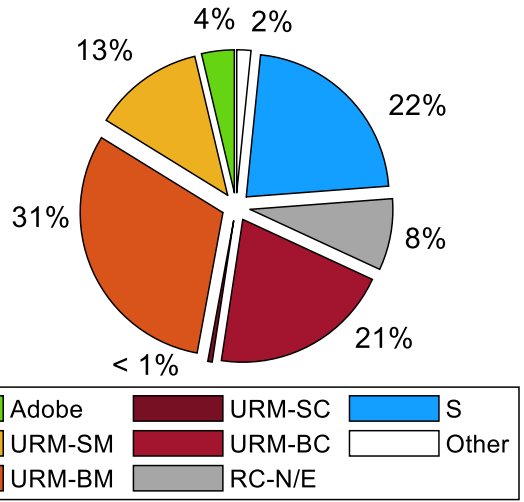

(c)

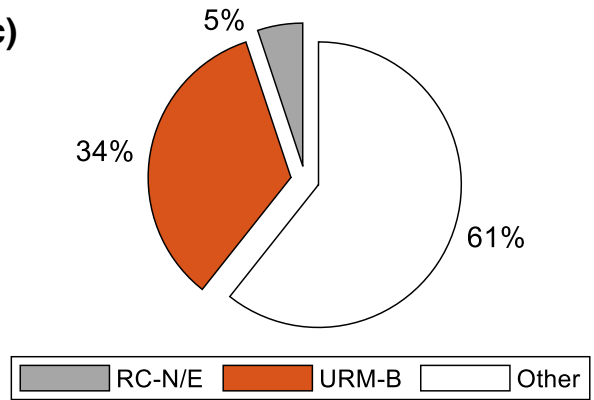

(b)

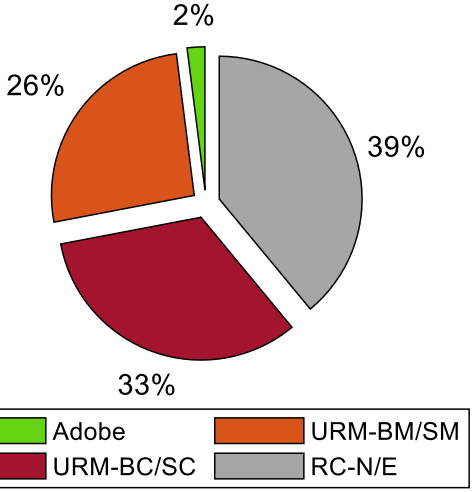

(d)

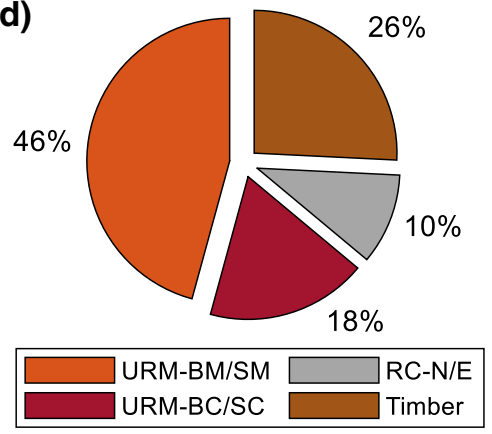

Fig. 2 a School typology distribution in the KV (NSET 2000), b building typology distribution in the Kathmandu Metropolitan area (Chaulagain et al. 2016), c school typology distribution in Nepal (Asian Development Bank 2014), d building typology distribution in Nepal (Gautam et al. 2018)

building type is the one-story steel structure. This typology represents $22 \%$ of the school building dataset. Lastly, reinforced concrete (RC) buildings account for $8 \%$ of the stock. For comparison purposes Fig. 2 reports additional building percentage distributions from other studies. In Fig. 2b, data from Chaulagain et al. (2016) show the general building stock distribution in the Kathmandu Metropolitan area. While the URM constructions still represent the $59 \%$ of the total stock, RC constructions account for $39 \%$ of the total. At national scale the comparison between school buildings and the general building portfolio is less accurate. ADB (Asian Development Bank 2014) provides a rough figure of school types (Fig. 2c) where 34\% of the total is brick masonry, 5\% is RC and the remaining part $(61 \%)$ refers to other typologies i.e., adobe, stone masonry, timber, mixed structures, etc. For residential buildings (Fig. 2d), Gautam et al. (2018) provides an indication from the last census data where buildings are categorized according to their foundation material: $46 \%$ of the building stock have brick-mud or stone-mud foundation, $18 \%$ brick-cement or stone-cement foundation, $10 \%$ have RC foundation and the remaining part (26\%) have timber pillars.

According to these statistics, URM buildings represent more than half the school/general building stock both at national scale and within the Kathmandu Valley. General characteristics of the three principal masonry school typologies (namely URM-SM, URM-BM and URM-BC) and recurrent seismic damage are discussed in the following subsections. 


\subsection{Rubble stone-mud masonry buildings [URM-SM]}

Stone-mud URM schools are mostly present in hills and mountain areas (Robinson et al. 2018). Generally, they are one-story buildings with story height between 1.8 and $2.4 \mathrm{~m}$. Walls are usually built with field stones whose shape and mechanical characteristics varies upon local availability. Their thickness is around $45-60 \mathrm{~cm}$. The wall has usually a multiple-leaf morphology and lacks of through-stones (Wang et al 2018). Adequate wall-to-wall and wall-to-floor connections are also absent in most of the cases with the exceptions of state-of-the-art constructions with adequately built rectangular corner stone (e.g., World Bank 2019b). Floors are constituted by a $10 \mathrm{~cm}$ mud-layer supported by wooden planks and timber/bamboo joists. Roof is commonly made of Corrugated Galvanized Iron (CGI) sheets supported by small timber beams.

As pointed out in numerous studies URM-SM are highly vulnerable to seismic actions (Gautam and Chaulagain 2016). Firstly, the absence of wall-to-wall and wall-to-floor connections results in frequent out-of-plane (OOP) damage (Sharma et al. 2016) as reported in Fig. 3a. Secondly, multi-leaf walls are affected by delamination under seismic shaking and, for this reason, the risk of OOP failure increases. Lastly, box-type response is essentially absent due to the high in-plane flexibility of the horizontal structures, so the walls behave almost independently being more vulnerable to OOP loads (Brando et al. 2017). These phenomena are obviously aggravated by the low and uncertain mechanical response of the mud-mortar.

\subsection{Brick-mud masonry buildings [URM-BM]}

In terai/hilly rural areas and in older city districts, it is likely to find URM school buildings made of fired bricks and mud-mortar (Robinson et al. 2018). URM-BMs have usually twostories and inter-story height around $2.7 \mathrm{~m}$. The thickness of the walls is around $35-45 \mathrm{~cm}$ (ARUP 2015). Fired brick mechanical properties can differ from region to region and are highly influenced by the production process, i.e., manual or industrial. Floors and roofs are usually realized with traditional techniques such as timber-mud and timber-CGI. In some cases, traditional floors have been replaced with RC slabs.

URM-BM buildings are affected by many structural weaknesses that influence their seismic response. Despite bricks are arranged in regular patterns (e.g. English bond), the construction quality is generally low (Brando et al. 2017). Lack of wall-to-wall and wallto-floor connections, lack of bonding between wall leaves, lack of seismic detailing (e.g. tie
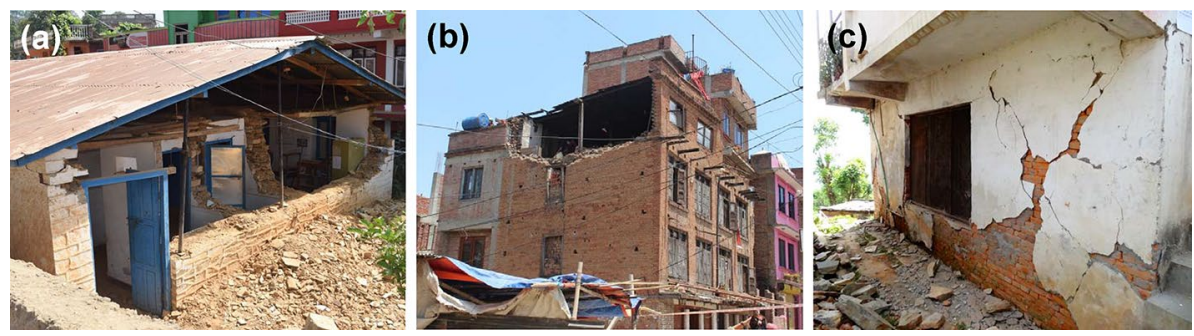

Fig. 3 a URM-SM OOP damage (credit: Suraj Shrestha, EERI photo archive), b URM-BM OOP damage at higher story (credit: Bipin Shrestha, EERI photo archive), c URM-BC IP damage (credit: Bret Lizundia, EERI photo archive) (EERI 2019) 
rods, anchors, ring beams, etc.) are common deficits of URM-BMs (Gautam et al. 2016). Due to the horizontal structure configuration, monolithic box-behavior is generally absent. For these reasons the predominant damage mode of URM-BM typology is the OOP, sometimes preceded by delamination (Brando et al. 2017). It has been observed that non-loadbearing walls and walls located at the upper stories are more vulnerable to OOP damage (Fig. 3b). This has been largely documented in numerous post 2015 earthquake reconnaissance reports (Chiaro et al. 2015; EERI 2016).

\subsection{Brick-cement masonry buildings [URM-BC]}

School buildings made of fired bricks in cement-mortar have been increasingly built in the last 30 years, especially in urban areas (NSET 2000). They are generally single storied buildings but, in some cases, can go up to four stories. Their average inter-story height is $2.7 \mathrm{~m}$ and are characterized by large openings. According to NSET (2000) and ARUP (2015) walls are generally one brick thick $(23-24 \mathrm{~cm})$ for single story and multi-story buildings while World Bank (2019b) reports multi-story URM-BC with thicker walls. URM-BCs have usually cast-in-place RC floors and roof.

Thanks to the presence of RC horizontal structures, they generally exhibit a box-behaviour response under seismic actions and in-plane (IP) damage of piers and spandrels is more recurrent (Fig. 3c). However, sometimes they lack adequate wall-to-wall/wall-to-floor connections and, consequently, suffer from OOP damage as well.

\section{Seismic assessment methodology}

The derivation of analytical fragility curves firstly requires the implementation of a proper seismic assessment methodology. This consist of four steps (Calvi et al. 2006):

(i) Definition of a numerical/analytical model for the considered structural typology. In this phase, the analyst selects the level of complexity of the structural simulation, ranging from analytical formulations to detailed numerical models. Several studies on URMs relies on simplified equations to define seismic capacity (D'Ayala and Speranza 2003; Lagomarsino and Giovinazzi 2006; Borzi et al. 2008; D’Ayala and Paganoni 2011). This seems a reasonable approach to be followed in the context of Nepal where advanced numerical techniques can be limited by the lack of building/ material data. Analytical formulations adopted in this study are reported in Sects. 3.1 and 3.2.

(ii) Selection of a seismic analysis method. Looking at previous literature studies, three main methods have been adopted to derive fragilities for URMs: nonlinear time history analysis (e.g. Park et al. 2009), incremental dynamic analysis (e.g. Rota et al. 2010) and nonlinear static analysis (e.g. Borzi et al. 2008; Frankie et al. 2012)). The latter method involves simplified capacity spectrum techniques such as the CSM (Freeman 1978) or the N2 (Fajfar 2000). Spectral approaches are certainly less advanced with respect to the other methods, but computationally faster and still quite reliable (e.g. Lagomarsino 2015; Lagomarsino and Cattari 2015). For these reasons, they seem a valid option for fragility assessment of Nepali URMs. Details on the seismic assessment method adopted in this study are reported in Sects. 3.3 and 3.4. 
(iii) Definition of criteria to identify damage states (DSs). In analytical fragility studies it is common practice to identify damage states as displacement thresholds on the capacity curve (e.g. Lagomarsino and Giovinazzi 2006; Simoes et al. 2015; Giordano et al. 2020b). For the case of masonry buildings affected by IP and OOP damage, multiple criteria have to be defined (e.g. Ceran and Erberik 2013; Ahmad et al. 2014). DS criteria considered in this work are described in Sect. 3.4.

(iv) Execution of the analysis and estimation of IMs for different DSs. Once DSs are defined, corresponding IMs are computed according to the methodology of point (ii).

The assessment methodology adopted in this study considers OOP and/or IP damage potential depending on the horizontal structure typology. As observed in the aftermath of the 2015 Gorkha earthquake (e.g. Brando et al. 2017), masonry buildings with traditional flexible floors cannot respond in a box-like manner and, therefore, are mostly affected by OOP damage (Giordano et al. 2020a). On the contrary, rigid RC slabs guarantee (EERI 2016): (i) a better wall-to-floor restraint against OOP and (ii) a uniform distribution of the seismic forces among bearing walls that, consequently, suffer from IP damage. Three recurrent URM categories are analysed in this work: URM-SM with traditional flexible floors, URM-BM with traditional flexible floors, URM-BC with rigid RC slabs. It is worth mentioning that these categories do not cover the entire masonry school building stock but, according to the literature (NSET 2000; ARUP 2015), represent a consistent proportion of the total. Interested readers can consult the Global Library of School Infrastructure (World Bank 2019b) for an extended collection of index school buildings in Nepal. Table 1 summarizes the damage considered for the different cases. Subsequently, CSM is adopted to estimate IMs for different DSs, as for previous studies (Lagomarsino and Cattari 2015; Giordano et al. 2020a).

\subsection{Out-of-plane capacity}

The OOP capacity of the constituting walls of the building is estimated with a closed-form mechanical-based formulation recently proposed by Giordano et al. (2019b, 2020a) that relies on the following assumptions:

- The OOP response of a vertically spanning URM wall is purely governed by bending (Griffith et al. 2004; Shawa et al. 2012; Ferreira et al. 2015; Degli Abbati and Lagomarsino 2017).

- Since the nonlinear flexural deformations localize in the areas with maximum bending moment (Ferreira et al. 2015; Degli Abbati and Lagomarsino 2017), the wall is modeled as a system of rigid bodies and nonlinear hinges.

Table 1 URM categories object of this study: horizontal structures typology and corresponding damage potential

\begin{tabular}{llll}
\hline Masonry typology & Floor/roof typology & Floor/roof stiffness & Damage potential \\
\hline URM-SM & Traditional & Flexible & OOP \\
URM-BM & Traditional & Flexible & OOP \\
URM-BC & RC slab & Rigid & OOP + IP \\
\hline
\end{tabular}


- The moment-rotation relationship of the nonlinear hinge is computed starting from the moment-curvature $(\mathbf{M}-\chi)$ diagram of the critical cross-section. The $\mathbf{M}-\chi$ is calculated under the assumption that axial strains behave linearly in bending i.e., URM sections remain plane (Cavaleri et al. 2005; Brencich and Felice 2009; Parisi et al. 2016; Giordano et al. 2017).

- The rotation $\theta$ is calculated through a constant integration of the critical cross-section's curvature over the integration length $\mathrm{L}_{\mathrm{i}}$.

The model is capable to represent three boundary configurations i.e., cantilever, pinned-pinned and clamped-clamped wall by introducing the quantity $h_{L V}$, i.e., the shear length of the wall. The integration length $\mathrm{L}_{\mathrm{i}}$ was calibrated through analytical-experimental comparisons (Giordano et al. 2020a).

Cantilever $\left(\mathrm{h}_{\mathrm{LV}}=\mathrm{h}\right)$

$$
\mathrm{F}=\frac{1}{\mathrm{~h}_{\mathrm{LV}} \alpha_{\mathrm{h}}} \begin{cases}\left(\frac{1}{12} \mathrm{E}_{\mathrm{m}} \mathrm{Bt}^{3} \frac{\Delta}{\mathrm{L}_{\mathrm{h}} \mathrm{h}_{\mathrm{LV}}}-\frac{\mathrm{W} \Delta}{2}-\mathrm{N} \Delta\right), & \Delta \leq \mathrm{L}_{\mathrm{i}} \mathrm{h}_{\mathrm{LV}} \frac{2(\mathrm{~W}+\mathrm{N})}{\mathrm{E}_{\mathrm{m}} \mathrm{Bt}^{2}} \\ {\left[(\mathrm{~N}+\mathrm{W})\left(\frac{\mathrm{t}}{2}-\sqrt{\frac{2 \mathrm{~L}_{\mathrm{i}} \mathrm{h}_{\mathrm{LV}}(\mathrm{N}+\mathrm{W})}{9 \mathrm{E}_{\mathrm{m}} \mathrm{B} \Delta}}\right)-\frac{\mathrm{W} \Delta}{2}-\mathrm{N} \Delta\right], \mathrm{L}_{\mathrm{i}} \mathrm{h}_{\mathrm{LV}} \frac{2(\mathrm{~W}+\mathrm{N})}{\mathrm{E}_{\mathrm{m}} \mathrm{Bt}^{2}} \leq \Delta \leq \mathrm{L}_{\mathrm{i}} \mathrm{h}_{\mathrm{LV}} \frac{\mathrm{f}_{\mathrm{mb}}^{2} \mathrm{~B}}{2 \mathrm{E}_{\mathrm{m}}(\mathrm{W}+\mathrm{N})}}\end{cases}
$$

Pinned-Pinned $\left(\mathrm{h}_{\mathrm{LV}}=\mathrm{h} / 2\right)$

$$
\mathrm{F}=\frac{2}{\mathrm{~h}_{\mathrm{LV}} \alpha_{\mathrm{h}}} \begin{cases}\left(\frac{1}{12} \mathrm{E}_{\mathrm{m}} \mathrm{Bt}^{3} \frac{\Delta}{\mathrm{L}_{\mathrm{i}} \mathrm{h}_{\mathrm{LV}}}-\frac{\mathrm{W} \Delta}{2}-\mathrm{N} \Delta\right), & \Delta \leq \mathrm{L}_{\mathrm{i}} \mathrm{h}_{\mathrm{LV}} \frac{2(\mathrm{~W}+\mathrm{N} / 2)}{\mathrm{E}_{\mathrm{m}} \mathrm{Bt}^{2}} \\ {\left[\left(\mathrm{~N}+\frac{\mathrm{W}}{2}\right)\left(\frac{\mathrm{t}}{2}-\sqrt{\frac{2 \mathrm{~L}_{\mathrm{i}} \mathrm{h}_{\mathrm{LV}}(\mathrm{N}+\mathrm{W} / 2)}{9 \mathrm{E}_{\mathrm{m}} \mathrm{B} \Delta}}\right)-\frac{\mathrm{W} \Delta}{2}-\mathrm{N} \Delta\right], \mathrm{L}_{\mathrm{i}} \mathrm{h}_{\mathrm{LV}} \frac{2(\mathrm{~W}+\mathrm{N} / 2)}{\mathrm{E}_{\mathrm{m}} \mathrm{Bt}^{2}} \leq \Delta \leq \mathrm{L}_{\mathrm{i}} \mathrm{h}_{\mathrm{LV}} \frac{\mathrm{f}_{\mathrm{mb}}^{2} \mathrm{~B}}{2 \mathrm{E}_{\mathrm{m}}(\mathrm{W}+\mathrm{N} / 2)}}\end{cases}
$$

Clamped-Clamped $\left(\mathrm{h}_{\mathrm{LV}}=\mathrm{h} / 4\right)$

$$
\mathrm{F}=\frac{2}{\mathrm{~h}_{\mathrm{LV}} \alpha_{\mathrm{h}}} \begin{cases}\left(\frac{1}{24} \mathrm{E}_{\mathrm{m}} \mathrm{Bt}^{3} \frac{\Delta}{\mathrm{L}_{\mathrm{i}} \mathrm{h}_{\mathrm{LV}}}-\frac{\mathrm{W} \Delta}{4}-\frac{\mathrm{N} \Delta}{2}\right), & \Delta \leq 2 \mathrm{~L}_{\mathrm{i}} \mathrm{h}_{\mathrm{LV}} \frac{2(\mathrm{~W}+\mathrm{N} / 2)}{\mathrm{E}_{\mathrm{m}} \mathrm{Bt}^{2}} \\ {\left[\left(\mathrm{~N}+\frac{\mathrm{W}}{2}\right)\left(\frac{\mathrm{t}}{2}-\sqrt{\frac{4 \mathrm{~L}_{\mathrm{i}} \mathrm{h}_{\mathrm{LV}}(\mathrm{N}+\mathrm{W} / 2)}{9 \mathrm{E}_{\mathrm{m}} \mathrm{B} \Delta}}\right)-\frac{\mathrm{W} \Delta}{4}-\frac{\mathrm{N} \Delta}{2}\right],} & 2 \mathrm{~L}_{\mathrm{i}} \mathrm{h}_{\mathrm{LV}} \frac{2(\mathrm{~W}+\mathrm{N} / 2)}{\mathrm{E}_{\mathrm{m}} \mathrm{Bt}^{2}} \leq \Delta \leq 2 \mathrm{~L}_{\mathrm{i}} \mathrm{h}_{\mathrm{LV}} \frac{\mathrm{f}_{\mathrm{mb}}^{2} \mathrm{~B}}{2 \mathrm{E}_{\mathrm{m}}(\mathrm{W}+\mathrm{N} / 2)}\end{cases}
$$

where $\mathrm{F}$ is the base shear of the wall, $\Delta$ is the maximum horizontal displacement (top displacement for cantilever configuration and mid-height displacement for pinned-pinned and clamped-clamped configurations), $\mathrm{E}_{\mathrm{m}}$ is the masonry elastic modulus, $\mathrm{B}$ is the width of the wall, $\mathrm{t}$ is the thickness, $\mathrm{N}$ is the vertical load at the top of the wall, $\mathrm{W}=\mathrm{B} \cdot \mathrm{t} \cdot \mathrm{h} \cdot \gamma_{\mathrm{m}}$ is the self-weight of the wall (h and $\gamma_{\mathrm{m}}$ are height and unit weight of the wall respectively) and $\mathrm{f}_{\mathrm{mb}}$ is the compressive limit of the units. $\alpha_{\mathrm{h}}$ is a non-dimensional coefficient ranging from 0 to 1 , which defines the position of the resulting seismic horizontal force over the height of the wall. For instance, it is equal to $2 / 3$ when an inverse triangular distribution is assumed (Doherty et al. 2002).

To adopt the CSM, force-displacement curves defined by Eqs. 2-4 are reported in a spectral acceleration $\left(\mathrm{S}_{\mathrm{a}}\right)$ versus spectral displacement $\left(\mathrm{S}_{\mathrm{d}}\right)$ plane (capacity curves, $\mathrm{CC}$ ). As for Doherty et al. (2002), the transformation is carried out with the following equations:

$$
\mathrm{S}_{\mathrm{a}}=\frac{\mathrm{F}}{\mathrm{M}_{\mathrm{e}}} ; \mathrm{M}_{\mathrm{e}}=\frac{\left(\sum_{\mathrm{i}=1}^{\mathrm{n}} \mathrm{m}_{\mathrm{i}} \delta_{\mathrm{i}}\right)^{2}}{\sum_{\mathrm{i}=1}^{\mathrm{n}} \mathrm{m}_{\mathrm{i}} \delta_{\mathrm{i}}^{2}}
$$




$$
\mathrm{S}_{\mathrm{d}}=\Delta \cdot \Delta_{\mathrm{e}} ; \Delta_{\mathrm{e}}=\frac{\sum_{\mathrm{i}=1}^{\mathrm{n}} \mathrm{m}_{\mathrm{i}} \delta_{\mathrm{i}}^{2}}{\sum_{\mathrm{i}=1}^{\mathrm{n}} \mathrm{m}_{\mathrm{i}} \delta_{\mathrm{i}}}
$$

where $M_{e}$ is the effective mass of the equivalent SDOF system estimated by discretizing the wall into a finite number of elements with mass $\mathrm{m}_{\mathrm{i}}$ and dimensionless modal displacement $\delta_{i} ; \Delta_{\mathrm{e}}$ is the effective dimensionless displacement of the SDOF. The CCs are independent from the width $\mathrm{B}$ of the wall.

\subsection{In-plane capacity}

The IP capacity is estimated through the approach proposed by Lagomarsino and Giovinazzi (2006). The method was formulated for non-engineered masonry buildings. The CC of the building is assumed as elastoplastic bilinear. In details, the maximum pseudo-spectral acceleration capacity $S_{a, y}$ of the structure is defined as follow:

$$
\mathrm{S}_{\mathrm{a}, \mathrm{y}}=0.5 \frac{\tau \alpha \xi\left(0.8+0.2 \mathrm{~N}_{\mathrm{S}}\right)}{\left(0.75+0.25 \mathrm{~N}_{\mathrm{S}}^{-0.75}\right) \sigma_{0}}
$$

where $N_{S}$ is the number of stories, $\alpha$ is the ratio between the effective resisting area of the building and its footprint, $\xi$ is a reduction parameter which considers the non-uniform contribution of piers and ranges from 0.8 to 1 . Values of $\tau$ and $\sigma_{0}$ are defined with the following equations:

$$
\begin{gathered}
\tau=\tau_{0} \sqrt{1+\frac{\sigma_{0}}{\tau_{0}}} \\
\sigma_{0}=\mathrm{N}_{\mathrm{S}} \mathrm{p}+\gamma_{\mathrm{m}} \alpha \mathrm{h}_{\mathrm{S}}\left(1+\left(\mathrm{N}_{\mathrm{S}}-1\right)^{1.3}\right)
\end{gathered}
$$

where $\tau_{0}$ is the masonry shear strength, $\mathrm{p}$ is the floor overload and $\mathrm{h}_{\mathrm{S}}$ is the interstory height. The elastic limit pseudo-displacement $S_{\mathrm{d}, \mathrm{y}}$ is defined starting from the Eurocode 8 (European Commitee for Standardization 2004) simplified estimation of the period of a masonry structure:

$$
\mathrm{T}=0.05 \cdot \mathrm{H}^{3 / 4}
$$

where $\mathrm{H}$ is the total height of the building. Subsequently $\mathrm{S}_{\mathrm{d}, \mathrm{y}}$ is estimated from $\mathrm{S}_{\mathrm{a}, \mathrm{y}}$ with the following well-known equation:

$$
\mathrm{S}_{\mathrm{d}, \mathrm{y}}=\mathrm{S}_{\mathrm{a}, \mathrm{y}} \frac{\mathrm{T}^{2}}{4 \pi^{2}}
$$

The ultimate pseudo-displacement $S_{\mathrm{d}, \mathrm{u}}$ is calculated as the minimum between the one related to soft-story collapse $S_{d, u s}$ and the one referred to uniform collapse mode $S_{d, u u}$.

$$
\mathrm{S}_{\mathrm{d}, \mathrm{us}}=\delta_{\mathrm{u}} \frac{\mathrm{N}_{\mathrm{S}} \mathrm{h}_{\mathrm{S}}}{\Lambda}
$$




$$
\mathrm{S}_{\mathrm{d}, \mathrm{uu}}=\delta_{\mathrm{u}} \mathrm{h}_{\mathrm{S}}+\mathrm{S}_{\mathrm{d}, \mathrm{y}}\left(1-\frac{\Lambda}{\mathrm{N}_{\mathrm{S}}}\right)
$$

where $\delta_{\mathrm{u}}$ is the masonry ultimate drift ratio and $\Lambda$ is the modal participation factor of the first natural mode calculated as follow:

$$
\Lambda=\left(\frac{2}{3}+\frac{1}{3 \mathrm{~N}_{\mathrm{S}}}\right)^{-1}
$$

\subsection{Seismic demand}

According to the CSM, the seismic demand is represented in terms of a spectral-acceleration versus spectral-displacement response spectrum, so called ADRS. The spectral shape of the ADRS is generally provided by building codes (European Commitee for Standardization 2004; ASCE/SEI 2010). For Eurocode 8, the spectral shape remains unchanged regardless the demand intensity. Therefore, when code-compliant spectral shapes are used for fragility curves derivation, record-to-record variability cannot be considered. To overcome this limitation, some studies adopted ADRS from recorded GMs. For instance, Shinozuka et al. (2000) expressed the seismic demand by: (i) selecting 80 real GMs and grouping them in intervals of $0.05 \mathrm{~g}$; (ii) calculating mean and mean \pm standard deviation ADRS spectra for each interval; (iii) intersecting these ADRS with a RC bridge CC to obtain corresponding fragilities. More recently, Rossetto et al. (2016) have included record-to-record variability in a nonlinear static procedure to derive fragility curves of RC buildings using 150 GMs from the SIMBAD (Selected Input Motions for displacement-Based Assessment and Design) database (Smerzini et al. 2014). They have also successfully validated the results with nonlinear time history analyses. The use of real ADRS has some drawbacks. Referring to masonry structures in OOP loading, Lagomarsino (2015) pointed out that the jagged shape could lead to inconsistent IM values for subsequent DSs. This issue does not occur when smooth code-like spectra are employed (Giordano et al. 2020a). A possible way to account for different ADRS shapes is to process GM records with smoothing spectrum procedures. For instance, Malhotra (2006) proposed coefficients for ADRS estimation from PGA, PGV (peak ground velocity) and PGD (peak ground displacement) of the GM record. This methodology is herein adopted to process and smoothen $467 \times 2=934$ horizontal GM records from the SIMBAD database (Smerzini et al. 2014). Resulting spectra are then used to account for record-to-record variability as described in Sect. 5. Figure 4a shows the subdivision of the SIMBAD GMs with respect to their PGA while Fig. $4 \mathrm{~b}$ reports an application of the smoothing procedure for a selected record (January 17, 1994 Northridge earthquake, Los Angeles-UCLA Grounds-station code 24,688). It is worth mentioning that when assessing the OOP damage of walls located at upper stories, the spectral demand should be properly modified to take into account the filtering effect of the supporting structure (Suarez and Singh 1987; Calvi and Sullivan 2014). In the present study the equations proposed by Lagomarsino (2015) are adopted. The amplified displacement response spectra $S_{\mathrm{d}, \text { amp. }}(\mathrm{T}, \mathrm{z})$ at level $\mathrm{z}$ of the building is defined as:

$$
\mathrm{S}_{\mathrm{d}, \mathrm{amp} .}(\mathrm{T}, \mathrm{z})=\max \left\{\mathrm{S}_{\mathrm{d}}(\mathrm{T}), \mathrm{S}_{\mathrm{d}, \mathrm{Z}}(\mathrm{T}, \mathrm{z})\right\}
$$

where $S_{d}(T)$ is the GM displacement response spectrum, and $S_{d, Z}(T, z)$ is: 


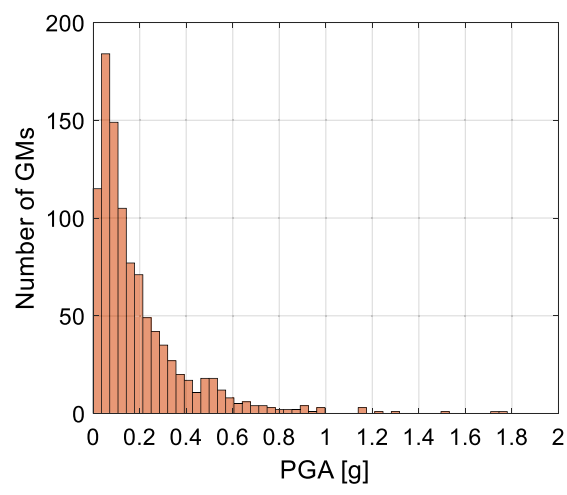

(a)

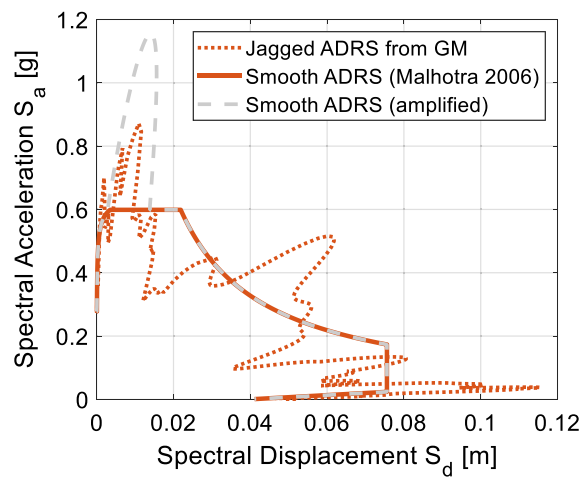

(b)

Fig. 4 a Subdivision of SIMBAD GM records by PGA, b comparison between jagged ADRS from GM record and smooth ADRS derived according to (Malhotra 2006). The grey-dotted line indicates the amplified spectrum at the first floor of a three-story building

$$
S_{d, Z}(T, z)= \begin{cases}S_{d}\left(T_{b}\right) \frac{\gamma_{b}\left|\psi_{b}(z)\right|\left(\frac{T}{T_{b}}\right)^{2}}{\sqrt{\left(1-\frac{T}{T_{b}}\right)^{2}+\frac{0.05}{\eta(\xi) \eta\left(\xi_{b}\right)} \frac{T}{T_{b}}}} & T<T_{b} \\ S_{d}(T) \frac{\eta(\xi) \eta\left(\xi_{b}\right) \gamma_{b}\left|\psi_{b}(z)\right|\left(\frac{T}{T_{b}}\right)^{2}}{\sqrt{\left(1-\frac{T}{T_{b}}\right)^{2}+0.05 \frac{T}{T_{b}}}} & T_{b} \leq T \leq 1.9 T_{b} \\ 3.8 \eta(\xi) \eta\left(\xi_{b}\right) \gamma_{b}\left|\psi_{b}(z)\right| S_{d}\left(T_{b}\right) \quad T>1.9 T_{b}\end{cases}
$$

where $T_{b}$ is the period of the supporting building as for Eq. (10), $\psi_{b}$ is the corresponding modal shape (linear shape assumption), $\gamma_{\mathrm{b}}=3 N_{S} /\left(2 N_{S}+1\right)$ is the coefficient of participation, $\eta(\xi)$ and $\eta\left(\xi_{\mathrm{b}}\right)$ are damping correction factors of the wall and of the supporting building respectively. The function $\eta(\xi)$ is defined in EC8, Part 1 (European Commitee for Standardization 2004). For illustrative purposes, Fig. 4b reports the amplified ADRS estimated at the first floor of a three-story building (total height $7.5 \mathrm{~m}$ ).

From the elastic response spectra, the inelastic demand is quantified by adopting the Capacity Spectrum Method (Freeman 1978). The CSM relies on the definition of an equivalent hysteretic damping of the structure that has been largely adopted to the case of masonry structures (e.g. Giordano et al. 2020a; Lagomarsino 2015; Borzi et al 2008). Additional details on the quantification of the overdamped spectra are reported in Sect. 3.4, point 4).

\subsection{Estimation of intensity measures for different DSs}

Once capacity and demand are defined, the estimation of IMs for different DSs is performed. According to previous fragility studies on masonry, PGA is adopted as IM (e.g. Borzi et al. 2008; Frankie et al. 2012; Simoes et al. 2015). This choice is motivated by several experimental campaigns (e.g. Benedetti et al. 1998) where PGA resulted a good damage predictor for stiff URM buildings subjected to IP damage. More controversial is the reliability of PGA in predicting OOP damage (Dimitrakopoulos and Paraskeva 2015). However, a recent research by Giresini et al. (2018) on the OOP fragility assessment of 
masonry walls has shown that PGA remains one of the most relevant IMs to predict OOP damage. Figure 5 reports the conceptual flowchart of the OOP and IP assessment procedures. For the OOP the following steps are needed (Fig. 5a) (Giordano et al. 2020a):

(1) Walls classification Identification of vulnerable walls with respect to their boundary conditions and overburden load. Referring to URMs with flexible floors/roof:

- Loadbearing walls located at the top-story (purple) are assumed with cantilever boundary configuration since flexible CGI roofs do not provide transversal top restrain to the walls (Brando et al. 2017). The presence of the roof translates in a vertical force on top of the wall and in a horizontal inertial load since the overburden is assumed to be unrestrained (Vaculik and Griffith 2017).

- Non-loadbearing walls located at the upper stories (green) are characterized by cantilever configuration that involves one or more stories. No vertical forces are transferred from the roof/floors to these walls.

- Non-loadbearing full-height walls (red) have cantilever boundary condition that spans over the entire height of the building. No vertical forces are transferred from the roof/floors to these walls.

- Loadbearing walls located at the lower stories (blue) are assumed with clampedclamped boundary configuration.

These boundary assumptions are consistent with previous studies on the topic (Doherty et al. 2002; Ceran and Erberik 2013). URMs with rigid floors/roof are characterized by clamped-clamped loadbearing configurations since RC bidirectional slabs generally insists on all the walls.

(2) Capacity curves calculation For any configuration, $\mathrm{S}_{\mathrm{a}}-\mathrm{S}_{\mathrm{d}} \mathrm{CC}$ are extracted with Eqs. 2-6.

\section{OOP assessment}

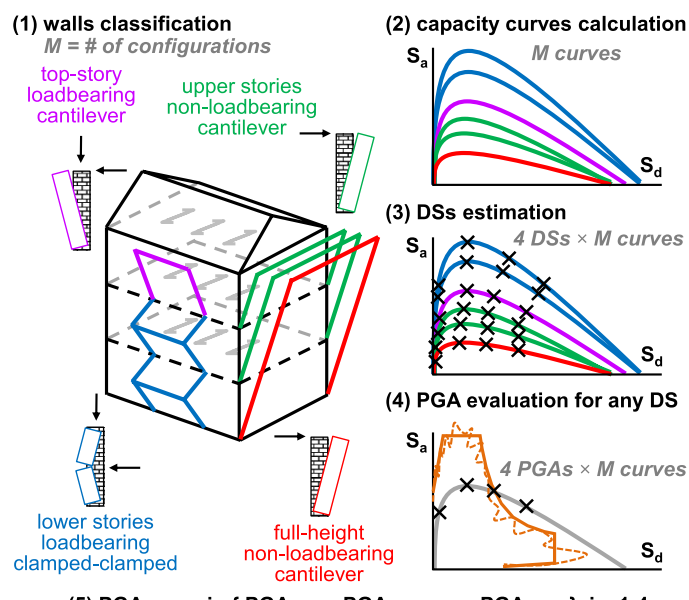

(5) $P G A_{D S I}=\min \left\{P G A_{D S i, 1} ; P G A_{D S I, 2} ; \ldots ; P G A_{D S i, M}\right\} i=1: 4$

(a)
IP assessment

(1) estimation of building resisting area $\alpha=$ resisting area / footprint
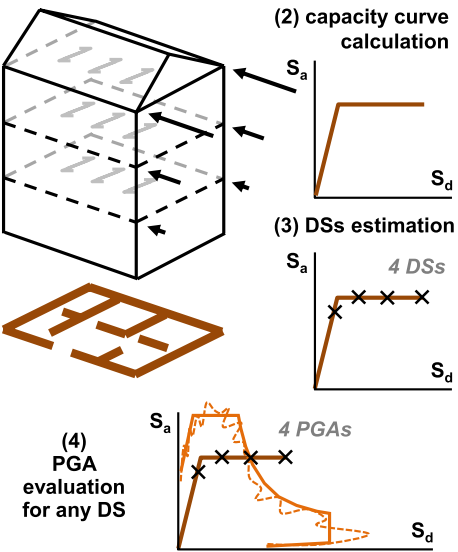

(b)

Fig. 5 Conceptual flowchart of the assessment procedures adopted in the study: a OOP, b IP 
(3) DSs estimation As underlined by Lagomarsino (2015) the definition of actual OOP physical damage of URM walls is quite complex when using analytical methods. Theoretically only two DSs should be considered: the rocking activation and the overturning. In between these two states, the wall should ideally rock without accumulating permanent damage. However, experimental evidence has shown that rocking generates cracks, crushes and sliding of units. In absence of specific physical-based definitions, in this work OOP DSs are calculated in terms of displacement thresholds on the CCs, as for Lagomarsino (2015):

- DS1 (slight damage): displacement at $70 \%$ peak $\mathrm{S}_{\mathrm{a}}$ capacity;

- DS2 (moderate damage) displacement at peak $\mathrm{S}_{\mathrm{a}}$ capacity;

- DS3 (severe damage): $25 \%$ of $\mathrm{S}_{\mathrm{d}, \mathrm{u}}$ i.e. displacement at null $\mathrm{S}_{\mathrm{a}}$ or displacement at cross-section failure (upper limit of $\Delta$ as for Eqs. 2-4);

- DS4 (near collapse): $40 \%$ of $\mathrm{S}_{\mathrm{d}, \mathrm{u}}$.

(4) PGA evaluation for any DS The PGA estimation is carried out with the CSM (Freeman 1978) as suggested by Lagomarsino and Cattari (2015). Starting from the $\left(\mathrm{S}_{\mathrm{d}, \mathrm{DSi}} ; \mathrm{S}_{\mathrm{a}, \mathrm{DSi}}\right)$ points over the $\mathrm{CC}$, corresponding periods $\mathrm{T}_{\mathrm{DSi}}$ are estimated:

$$
\mathrm{T}_{\mathrm{DSi}}=2 \pi \sqrt{\frac{\mathrm{S}_{\mathrm{d}, \mathrm{DSi}}}{\mathrm{S}_{\mathrm{a}, \mathrm{DSi}}}}
$$

subsequently the equivalent damping coefficient $\xi_{\mathrm{DSi}}$ for any DS is calculated:

$$
\xi_{\mathrm{DSi}}=\xi_{0}+\xi_{\mathrm{h}, \mathrm{MAX}}\left(1-\frac{1}{\mu_{\mathrm{DSi}}^{\varsigma}}\right)
$$

where $\xi_{0}$ is the initial damping of the masonry structure, $\xi_{\mathrm{h}, \mathrm{MAX}}$ is the asymptote of the hysteretic damping which depends on the structure type and $\mu_{\mathrm{DSi}}^{\varsigma}$ is the displacement ductility defined as $\mathrm{S}_{\mathrm{d}, \mathrm{DSi}} / \mathrm{S}_{\mathrm{d}, \mathrm{DS} 1}$ ( $\varsigma$ ranges between 1 and 2 ). Lastly, the PGA is estimated by calculating the normalized ADRS (PGA $=1.0 \mathrm{~g}$, damping equal to $\xi_{\mathrm{DSi}}$ ) and by homothetically scaling the spectrum to intersect the CC at the given DS (Lagomarsino and Cattari 2015; Giordano et al. 2020a). As discussed in Sect. 3.3, for walls located at the upper stories, the ADRS shape is modified to account for the filtering effect of the supporting building. Once DS PGAs are calculated for each wall configuration, at any DS the minimum is extracted as representative of the whole building.

The IP assessment is executed with the following procedure (Fig. 5b):

(1) Estimation of the building resisting area (Sect. 3.2).

(2) Capacity curve calculation (Sect. 3.2).

(3) DSs estimation. Displacement thresholds are evaluated over the CC with the criteria by Lagomarsino and Giovinazzi (2006) where corresponding physical damage is defined according to EMS-98 (Grünthal 1998):

- DS1 (slight damage): displacement at $0.7 \mathrm{~S}_{\mathrm{d}, \mathrm{y}}$;

- DS2 (moderate damage): displacement at $1.5 \mathrm{~S}_{\mathrm{d}, \mathrm{y}}$;

- DS3 (severe damage): displacement at $0.5 \times\left(\mathrm{S}_{\mathrm{d}, \mathrm{y}}+\mathrm{S}_{\mathrm{d}, \mathrm{u}}\right)$;

- DS4 (near collapse): displacement at $\mathrm{S}_{\mathrm{d}, \mathrm{u}}$. 
Definitions of $S_{\mathrm{d}, \mathrm{y}}$ and $\mathrm{S}_{\mathrm{d}, \mathrm{u}}$ are reported in Sect. 3.2.

(4) PGA evaluation for any DS. PGAs calculation is performed as for OOP assessment.

\section{Probabilistic input variables for Monte Carlo simulations}

OOP and IP assessment procedures described in Sect. 3.4 are used to derive fragility curves for Nepalese URM school buildings by performing Monte Carlo simulations where input parameters variability is directly taken into account. Monte Carlo is a standard statistical technique that is mainly adopted in combination with low-computational cost models (D'Ayala et al. 2015) such as the ones described in Sect. 3. Four main sources of uncertainty are considered: (i) intra-building variability, e.g., mechanical properties, material density, acting loads, etc.; (ii) inter-building variability e.g., number of stories, interstory height, walls thickness etc.; (iii) CSM parameters variability; (iv) record-to-record variability.

Depending on the floor typology, OOP or OOP + IP assessment is carried out (Table 1). When OOP + IP is executed, resulting DS PGAs are the minimum values between OOP and IP estimations for any Monte Carlo realization. In Sects. 4.1, 4.2 and 4.3 points (i), (ii) and (iii) are discussed for the three considered structural typologies while point (iv) is addressed in Sect. 5.

\subsection{Rubble stone-mud masonry buildings [URM-SM]}

As reported in Table 1, URM-SMs are assessed with respect to the OOP damage potential. For the geometrical parameters, indications provided by ARUP (2015) and NSET (2000) are considered. The story height $h_{S}$ is assumed normally distributed around a mean $(\mu)$ of $2.1 \mathrm{~m}$ with lower/upper truncation at $1.8 \mathrm{~m}$ and $2.4 \mathrm{~m}$ respectively. The coefficient of variation $(\mathrm{CoV})$ is assumed equal to 0.3 as in Ahmad et al. (2018). The midspan of the flooring system $\mathrm{L}_{\mathrm{M}}$, which is required to compute the walls acting load, is represented by a truncated normal distribution with $\mu=2.0, \mathrm{CoV}=0.3$ and $\mathrm{max} / \mathrm{min}$ at $1.5 \mathrm{~m}$ and $2.5 \mathrm{~m}$. Lastly, the walls thickness is uniformly distributed between 45 and $60 \mathrm{~cm}$ (ARUP 2015). An important aspect of the OOP analysis is to quantify the effect of inadequate transversal bond on the wall capacity (i.e., presence of multiple and poorly connected wythes). Lagomarsino (2015) suggests decreasing the wall flexural stiffness (and consequently the OOP capacity) by introducing a modified thickness $t^{\prime}=\kappa \mathrm{t}$, where $\kappa$ is a non-dimensional reduction factor $(\kappa<1)$. $t$ ' does not modify the self-weight of the wall (still estimated with $t$ ) but solely applies when calculating the flexural stiffness and strength of the cross-section. An extensive numerical study by de Felice (2011) has shown that OOP strength and displacement capacity is highly affected by the bond between masonry layers. Particularly, a comparison between rigid-body analysis and discrete element analysis which accounted for the real cross-section geometry was carried out. It was observed that: (i) the average discrepancy of the two modelling approaches is around 30\%; (ii) when the transversal bond is particularly weak, as for Nepalese stone walls (Brando et al. 2017), the overestimation of the rigid-body can go up to $70 \%$. Recent experimental investigations by Giaretton et al. (2017) has also shown a systematic delamination of stone walls where approximately $2 / 3$ of the cross section detaches and fails in OOP. Given these observations, for the URM-SM 
typology, a uniform distribution of $\kappa$ is considered with lower/upper limit equal to 0.3 and 0.7 respectively. The modified thickness t' (and consequently $t$ and $\kappa$ ) is a key input parameter for OOP assessment. This has been observed in a recent study by the authors on the sensitivity of out-of-plane capacity to input parameters of Nepali walls (Giordano et al. 2019a). Therefore, the probabilistic model of $\kappa$ should be improved as soon as regional OOP experimental results become available.

Masonry properties required for the OOP assessment are taken from previous literature studies. As suggested in the Probabilistic Model Code (JCSS 2011), lognormal distributions are considered for material characteristics. The elastic modulus $\mathrm{E}_{\mathrm{m}}$ of rubble stone masonry in mud mortar provided in World Bank (2019a) is adopted. This results in $\mu=240 \mathrm{MPa}$. In absence of specific information on the dispersion, $\mathrm{CoV}=0.30$ is considered. The compressive strength of the units $f_{m b}$ is derived from the stone properties reported in the Indian Standards (Bureau of Indian Standards 1974). This results in $\mu=25 \mathrm{MPa}$ and $\mathrm{CoV}=0.28$. Lastly the average specific weight of masonry $\gamma_{\mathrm{m}}$ is assumed at $22 \mathrm{kN} / \mathrm{m}^{3}$ (Bureau of Indian Standards 1987) while the CoV is assumed equal to 0.05 (JCSS 2001). Due to the lack of experimental data on Nepali masonry and the uncertainties around its response, the mechanical parameters have been assumed as non-correlated. An analogous simplification can be found in previous literature works (e.g. Ahmad et al 2018; Park et al 2009).

Variability of the CGI roof load $\mathrm{p}_{\mathrm{R}}$ is estimated from the Indian Standards (Bureau of Indian Standards 1987) by considering different type of CGI sheets and geometrical variation of the supporting timber/bamboo beams. This results in a lognormal distribution with $\mu=0.15 \mathrm{kN} / \mathrm{m}^{2}$ and $\mathrm{CoV}=0.22$. The floor load $\mathrm{p}_{\mathrm{F}}$ considers variability from: (i) geometry of the wooden supporting system (i.e. beam spacing, beam cross-section, planks thickness); (ii) timber specific weight (lognormal distribution with $\mu=5 \mathrm{kN} / \mathrm{m}^{3}$ and $\mathrm{CoV}=0.10$ (JCSS 2001)); (iii) mud-layer specific weight (uniform distribution between 17.25 and $18.85 \mathrm{kN} /$ $\mathrm{m}^{3}$ (Bureau of Indian Standards 1987)); (iv) mud-layer thickness (uniform distribution between 8 and $12 \mathrm{~cm}$ ); (v) prescribed live load (normal distribution with $\mu=0.3 \times 3 \mathrm{kN} /$ $\mathrm{m}^{2}=0.9 \mathrm{kN} / \mathrm{m}^{2}$ as for Indian Standards (Bureau of Indian Standards 1987) and CoV $=0.25$ (JCSS 2001)). The combination of these probabilities results in a lognormal distribution of $\mathrm{p}_{\mathrm{F}}$ with $\mu=3.12 \mathrm{kN} / \mathrm{m}^{2}$ and $\mathrm{CoV}=0.10$.

Variability of the CSM parameters, namely $\xi_{0}$, $\xi_{\mathrm{h}, \mathrm{MAX}}$ and $\varsigma$, are also considered. According to previous studies (Lagomarsino 2015), $\xi_{0}$ of masonry structures ranges between 3 and $5 \% . \xi_{\mathrm{h}, \mathrm{MAX}}$ is described by a truncated normal distribution with $\mu=10 \%$, $\mathrm{CoV}=0.3$ and $\mathrm{min} / \mathrm{max}$ at $5 \%$ and $20 \%$ (Giordano et al. 2020a). Analogously $\varsigma$ has $\mu=1.5$, $\mathrm{CoV}=0.3$ and $\mathrm{min} / \mathrm{max}$ equal to 1 and 2 (Lagomarsino and Cattari 2015). Table 2 summarizes the probabilistic input parameters for the OOP assessment of URM-SM.

\subsection{Brick-mud masonry buildings [URM-BM]}

For the case of URM-SM, geometric properties are taken from ARUP (2015) and NSET (2000). Story height $h_{S}$ is assumed normally distributed with $\mu=2.7 \mathrm{~m}, \mathrm{CoV}=0.30$ (Ahmad et al. 2018) and lower/upper truncation at $2.4 \mathrm{~m}$ and $3.0 \mathrm{~m} . \mathrm{L}_{\mathrm{M}}$ is assumed with the same distribution function of URM-SM. Walls thickness ranges between 35 and $45 \mathrm{~cm}$ while $\kappa$ is assumed uniformly distributed between 0.7 and 1 to account for possible ineffective bond at cross-section level (Brando et al. 2017).

Lognormal distributions are assumed for material properties with mean values derived from the experimental tests on Nepali brick-mud masonry carried out by Rits-DMUCH 


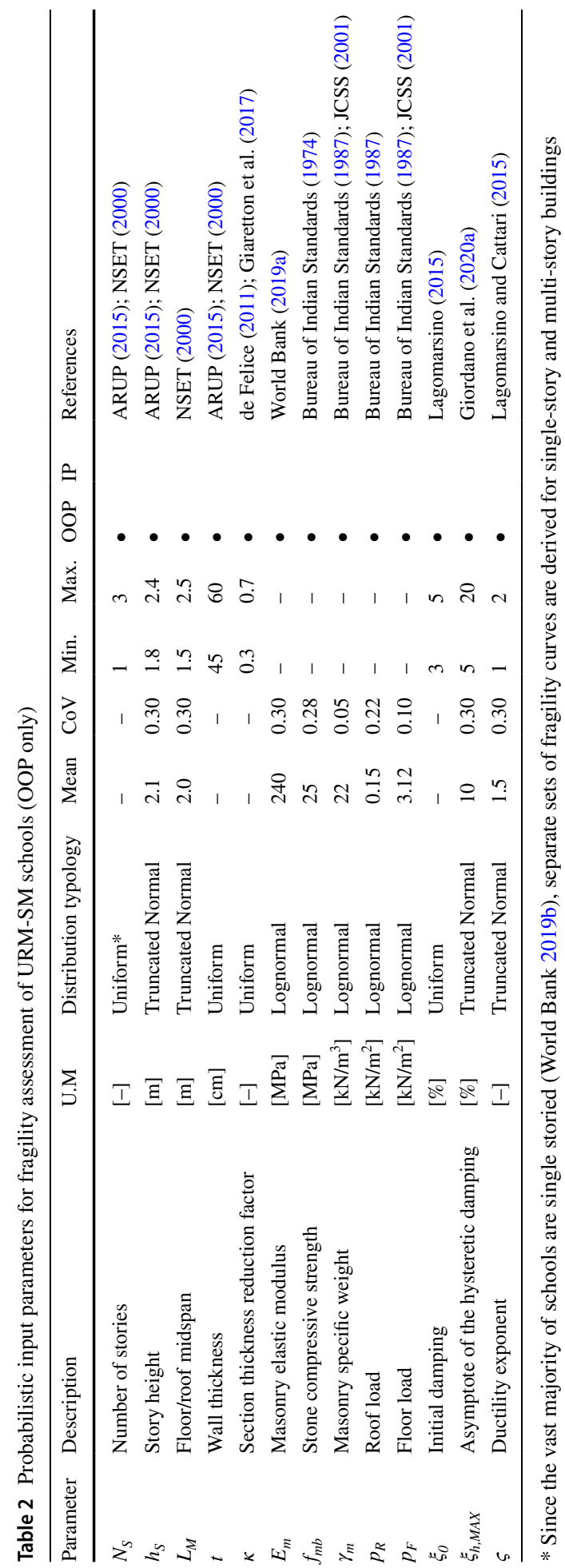


(2012) and CoVs from JCSS $(2001,2011)$. In detail: $\mu\left(E_{m}\right)=794 \mathrm{MPa}, \operatorname{CoV}\left(E_{m}\right)=0.25$; $\mu\left(f_{m b}\right)=11.03 \mathrm{~m}, \operatorname{CoV}\left(f_{m b}\right)=0.17 ; \mu\left(\gamma_{m}\right)=17.68 \mathrm{kN} / \mathrm{m}^{3}, \operatorname{CoV}\left(\gamma_{\mathrm{m}}\right)=0.05$. Regarding the loads, probabilistic distributions reported in 4.1. are considered valid for URM-BM as well. Lastly, CSM parameters variability is treated as in URM-SM. Table 3 summarizes the input probability functions for the OOP assessment. It is specified that probabilistic distributions and mean values adopted in this work are like the ones reported in a previous study by the authors (Giordano et al. 2019b) while dispersions are taken form JCSS (2001, 2011).

\subsection{Brick-cement masonry buildings [URM-BC]}

Given the presence of rigid RC slabs, URM-BC buildings are assessed for IP + OOP damage potential. Geometric parameters are derived from ARUP (2015) and NSET (2000). Specifically, $\mathrm{h}_{\mathrm{S}}$ and $\mathrm{L}_{\mathrm{M}}$ are assumed with same distributions as URM-BM. Since brick cement walls are mostly one-brick thick, a narrow band for the thickness distribution is considered $(23 \mathrm{~cm}-24 \mathrm{~cm})$ and $\kappa$ is assumed equal to 1 . To execute the IP assessment, $\alpha$ (i.e. the ratio between the ground floor walls area and the footprint of the building) is also required. This quantity is generally correlated to the main geometric characteristics of the building (e.g., number of stories, horizontal structures span, etc.). However, in informal/ non-engineered URM Nepalese constructions this correlation can be very weak (for example it is quite common to see URMs where stories have been added during the years without making modification at the ground floor bearing walls). Therefore, in absence of specific data for Nepal, $\alpha$ is assumed uniformly distributed between 0.10 and 0.2 as suggested by Lagomarsino and Giovinazzi (2006).

As pointed out by Adhikari and D'Ayala (2019), material properties of Nepalese masonry can vary considerably due to the different state of deterioration of the material. As a consequence, in-situ tests generally provides lower values with respect to laboratory tests. To be consistent with the previous typologies, existing laboratory tests are adopted to characterize brick-cement URM. Material properties are considered lognormally distributed with CoV taken from JCSS (2011). In absence of specific data for Nepalese BCURM, mean values are extrapolated from experimental works on typical brick URMs in the Himalayan region (Shahzada et al. 2012; Javed et al. 2015). Therefore: elastic modulus $\mathrm{E}_{\mathrm{m}}$ is assumed with $\mu=1263 \mathrm{MPa}$ and $\mathrm{CoV}=0.25$; shear strength $\tau_{0}$ has $\mu=0.14 \mathrm{MPa}$ and $\mathrm{CoV}=0.40$. Compressive strength of the bricks $\mathrm{f}_{\mathrm{mb}}$ is assumed as for URM-BM. Lastly, the ultimate drift capacity ratio $\delta_{\mathrm{u}}$ needs to be defined for the IP analysis. Given the lack of experimental data on Nepalese URM-BC buildings, literature works on Pakistani URMs are used as a reference for $\delta_{\mathrm{u}}$. Particularly: (i) building-scale test performed by Shahzada et al. (2012) resulted in $\delta_{\mathrm{u}}=0.50 \%$; (ii) 4 perforated wall-scale tests by Sajid et al. (2018) gave $\delta_{u}$ values in the range of $0.30 \%$ and $0.50 \%$; (iii) with an extended experimental campaign, Javed et al. (2015) estimated $\delta_{u}$ at pier-scale obtaining $\mu=0.54 \%, \mathrm{CoV}=0.37$ and lower/upper limits of $0.28 \%$ and $1.05 \%$ respectively. Given the reasonable consistency of the three studies, the last statistical parameters are considered in this work to generate a truncated lognormal distribution for $\delta_{\mathrm{u}}$.

Average specific weight of URM-BC is assumed equal to $18 \mathrm{kN} / \mathrm{m}^{3}$ (Bureau of Indian Standards 1987) and CoV $=0.05$ (JCSS 2001). Variability of the RC horizontal structure load is estimated considering: (i) nominal floor thickness between 10 and $20 \mathrm{~cm}$ (Bureau of 


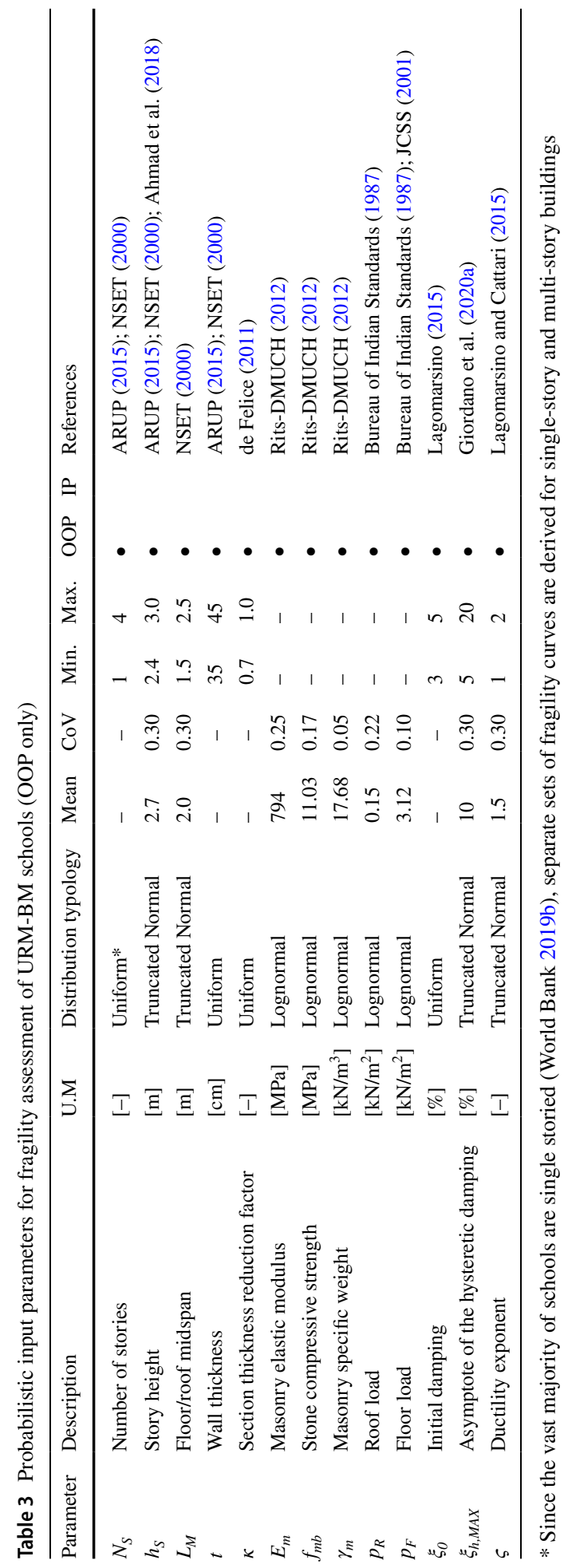


Indian Standards 1987); average specific weight of RC equal to $25 \mathrm{kN} / \mathrm{m}^{3}$ and $\mathrm{CoV}=0.04$ (JCSS 2001).

Lastly, CSM parameters variability is treated differently for the OOP and IP assessment since box-behavior response lead to consistently larger $\xi_{\mathrm{h}, \mathrm{MAX}}$ values (Lagomarsino and Cattari 2015). Resulting probabilistic distribution parameters for URM-BC are reported in Table 4.

\section{Monte Carlo analysis results}

Monte Carlo simulations are performed by randomly generating $\mathrm{N}=10,000$ combinations of the input parameters in Tables 2, 3, 4. According to Byrne (2013), this allows to achieve a confidence level of $95 \%$ to obtain a mean result within $1 \%$ of the exact solution for $\mathrm{CoV}$ up to 0.5. For one structural typology, Monte Carlo tests have been performed with larger $\mathrm{N}$ showing that 10,000 is sufficient to achieve the prescribed accuracy. Record-to-record variability is accounted by adopting the following procedure:

(i) For a given DSi displacement threshold on the $\mathrm{CC}$ of one Monte Carlo realization, a set of $\mathrm{PGA}_{\mathrm{DSi}, \mathrm{k}}, \mathrm{k}=1:$ 934, is estimated with the procedure represented in Fig. 5a, b (step (4)) and described in Sect. 3.4. (point 4)). 934 represents the number of SIMBAD records (Smerzini et al. 2014) converted to smoothed ADRS spectra with the procedure by Malhotra (2006). In Fig. 6a an example of $\mathrm{PGA}_{\mathrm{DSi}, \mathrm{k}}$ assessment is reported. The CC refers to the OOP of a cantilever wall of a single-story URM-SM building. It is observed that the 934 SIMBAD smoothed spectra intersect the $\mathrm{CC}$ at the given displacement damage threshold, in this case DS1.

(ii) Each of these 934 spectra provides a $\mathrm{PGA}_{\mathrm{DS} 1, \mathrm{k}}$ and a corresponding scale factor $\mathrm{SF}_{\mathrm{DS} 1, \mathrm{k}}=\mathrm{PGA}_{\mathrm{DS} 1, \mathrm{k}} / \mathrm{PGA}_{\mathrm{GM}, \mathrm{k}}$, where $\mathrm{PGA}_{\mathrm{GM}, \mathrm{k}}$ is the original PGA of the k-th GM record. Depending on the direction of the scaling, $\mathrm{SF}_{\mathrm{DS} 1, \mathrm{k}}$ can be larger than one (the $\mathrm{k}$-th spectrum is scaled up) or lower than one (the $\mathrm{k}$-th spectrum is scaled down). To quantify the absolute scaling, the quantity $\max \left\{\mathrm{SF}_{\mathrm{DS} 1, \mathrm{k}} ; 1 / \mathrm{SF}_{\mathrm{DS} 1, \mathrm{k}}\right\} \geq 1$ is defined. Figure $6 \mathrm{~b}$ reports the empirical cumulative distribution of this value for the considered example. The majority of the SIMBAD spectra intersect the $\mathrm{CC}$ with large and unrealistic absolute scale factors. It is also observed that the $10^{\text {th }}$ percentile of the distribution is 1.3 . This means that by selecting a subset of 100 spectra (approximately $10 \%$ of the SIMBAD database) the absolute scale factor is maintained close to one and considerably lower than the maximum allowable values suggested in the literature (Bommer and Acevedo 2004). Therefore, a subset of $100 \mathrm{PGA}_{\mathrm{DS} 1, \mathrm{k}}$ is selected. The dimension of the subset is comparable to the number of spectra used for record-to-record variability in previous studies (e.g., Rossetto et al. 2016).

(iii) The last step of the procedure is to randomly select one PGA value of the subset to define the final $\mathrm{PGA}_{\mathrm{DSi}}$. Referring to the example, Fig. 6c reports the empirical frequency distributions of $\mathrm{PGA}_{\mathrm{DS} 1, \mathrm{k}}$. It is observed that the subset of 100-GM PGAs ranges in the same interval of the total set of 934 SIMBAD-GM PGAs. This means that the selection by minimum absolute scale factors doesn't affect consistently the record-to-record variability. 


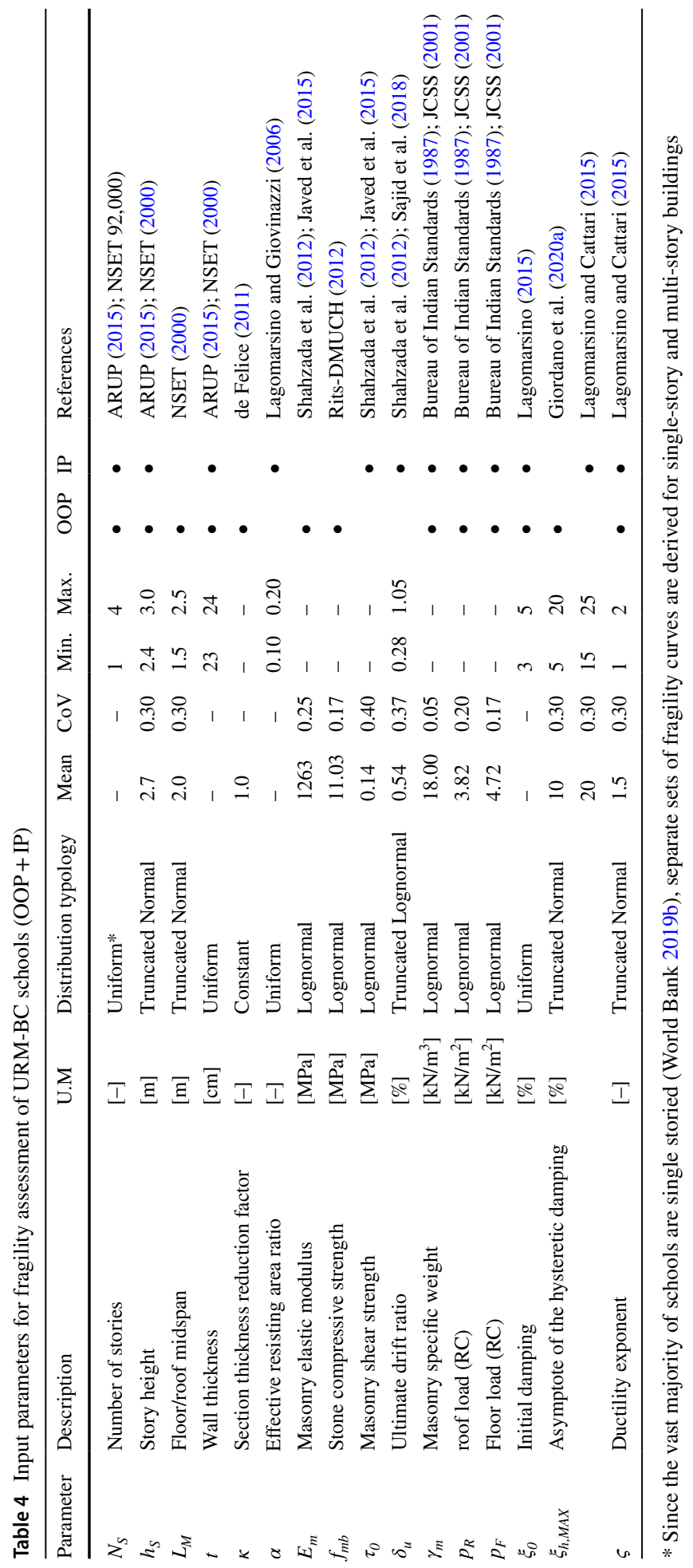




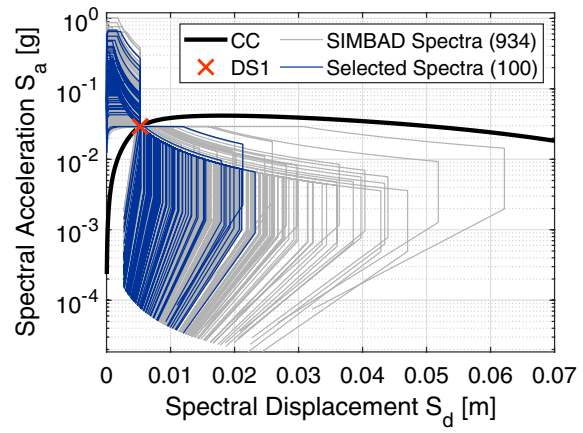

(a)

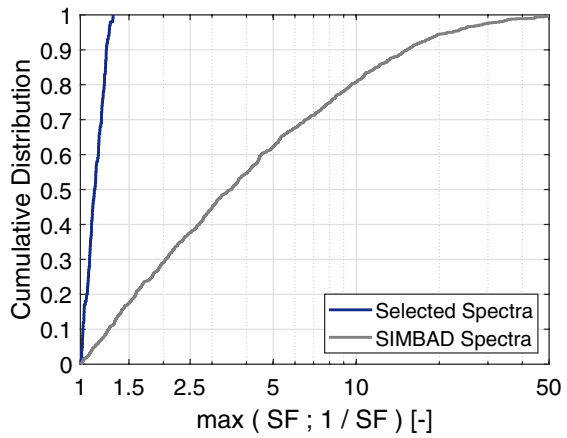

(b)

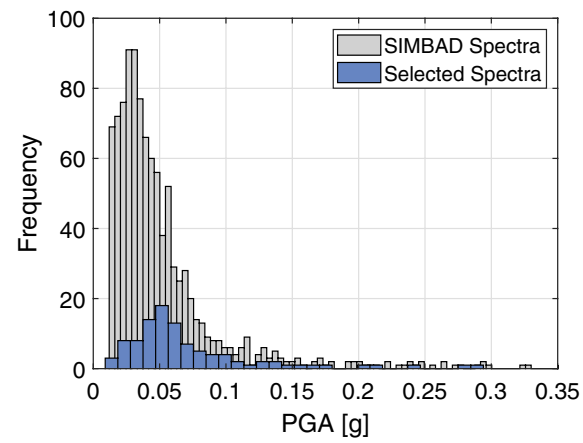

(c)

Fig. 6 Example of treatment of record-to-record variability: a intersections between ADRS spectra and $\mathrm{CC}$; $\mathbf{b}$ empirical cumulative distributions of absolute scale factor; $\mathbf{c}$ empirical frequency distribution of estimated PGAs for the whole SIMBAD database and the selected subset

To ensure the consistency of the results, $\mathrm{PGA}_{\mathrm{DS} \#}$ of each Monte Carlo realization should respect the consequential order of DS i.e. $\mathrm{PGA}_{\mathrm{DSi}} \geq \mathrm{PGA}_{\mathrm{DSi}-1}, \mathrm{i}=2,3,4$. This is always valid when adopting a single spectral shape for all the DS. Therefore, when different ADRS shapes are used, conflicting PGA $_{\mathrm{DS}}$ could occur. To overcome this issue, the following check is performed:

$$
\text { if }\left(\mathrm{PGA}_{\mathrm{DSi}}<\mathrm{PGA}_{\mathrm{DSi}-1}\right) \Rightarrow\left(\mathrm{PGA}_{\mathrm{DSi}} \underline{=} \underline{\underline{\text { def }}} \mathrm{PGA}_{\mathrm{DSi}-1}\right) \quad \forall \mathrm{i} \geq 2
$$

To quantify the different vulnerability of one-story and multistory buildings, the Monte Carlo analysis is repeated for six cases: (i) URM-SM1, single story; (ii) URM-SM23, twoto-three stories; (iii) URM-BM1, single story; (iv) URM-BM24, two-to-four stories; (v) URM-BC1, single story; (vi) URM-BC24, two-to-four stories. Among the various probability models suitable for fragility curves definition (De Risi et al. 2017), lognormal distribution is considered in this study. Figure 7 reports the cumulative distribution functions from the Monte Carlo analysis of URM-SM1 and the comparison with lognormal fits, where the method of maximum moments is adopted for the fitting.

Figure 8 reports the fragility curves obtained from the Monte Carlo analyses while Tables 5, 6, 7 summarize the corresponding statistical parameters (median $\eta$ and logarithmic standard deviation $\beta$ ). As expected, it can be observed that the presence of rigid 
Fig. 7 Cumulative distribution of PGAs ${ }_{\mathrm{DS}}$ for URM-SM1 from Monte Carlo simulations and corresponding lognormal fits

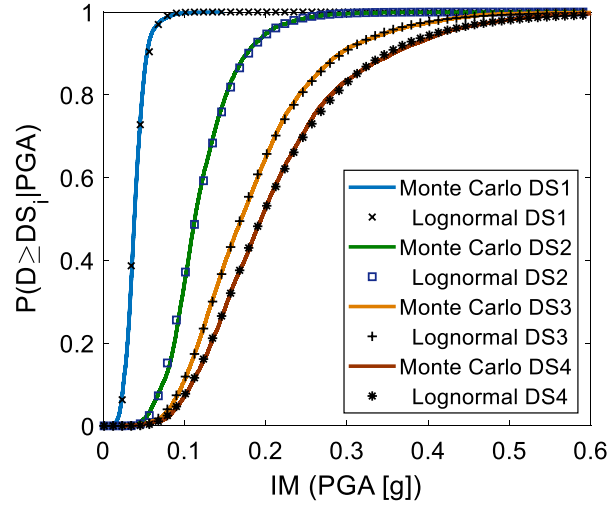

floors in URM-BC buildings (Fig. 8e) results in a better performance of this category with respect to URM-SM and URM-BM (Figs. $8 \mathrm{a}-\mathrm{c}$ ).

Table 8 reports the breakdown of the Monte Carlo results with respect to the governing damage mechanisms. Single-story buildings with flexible lightweight roof (URM-SM1 and URM-BM1) are governed by the OOP of loadbearing and non-loadbearing walls in equal parts. This result reflects the post-earthquake field observations. The overload of a CGI roof is almost irrelevant and does not provide any kinematic restraint against OOP displacement. Multi-story buildings with flexible floor/roof (URM-SM23 and URM-BM24) are ruled by three damage mechanisms. Particularly, the OOP of non-loadbearing walls at upper stories (green walls in Fig. 5a) is the governing mechanism in most of the analyses (41\% for URM-SM23 and $48.7 \%$ for URM-BM24). Loadbearing walls at lower levels (blue walls in Fig. 5a) are less vulnerable to OOP loads and, consequently, do not affect the fragility results. OOP is the governing damage mode in $63.5 \%$ of the analyses of single-story URM-BC buildings while IP is more critical in $36.5 \%$ of the cases. For multistorey URM-BC buildings the percentage of IP and OOP is $56 \%$ and $43.7 \%$ respectively. As for the previous building categories, the OOP damage of loadbearing walls at lower levels is not a critical damage pattern. In general, the analytical results are in line with post-earthquake observations (e.g. Brando et al. 2017) that report consistent OOP damage of non-loadbearing walls and at the higher stories of URM-SM/BM buildings (Giordano et al. 2020a). On the contrary, IP damage resulted critical for URM-BC buildings with stiff floors/roof (EERI 2016).

To compare the results of this study with the existing fragility curves for Nepali URMs, an equivalence for different definitions of damage states is needed. As previously said, DS1, DS2, DS3 and DS4 of this study are consistent with the EMS-98 definition (Grünthal 1998). This agrees relatively well with the DS classification adopted by Guragain (2015) (i.e. slight, moderate, severe, collapse). On the contrary, Chaulagain et al. (2016) and Gautam et al. (2018) studies are based on three DSs, therefore the comparison is carried out for DS2, DS3 and DS4.

- Comparison with observational fragility curves for residential buildings by Gautam et al. (2018)-URM-SM1 and URM-SM-23 (Fig. 7a) results are conservative with respect to observational fragilities derived by (Gautam et al. 2018) (Fig. 7b). For any DS, median values are approximately $50 \%$ of the corresponding empirical estimations. Furthermore, lognormal standard deviations estimated analytically are lower 


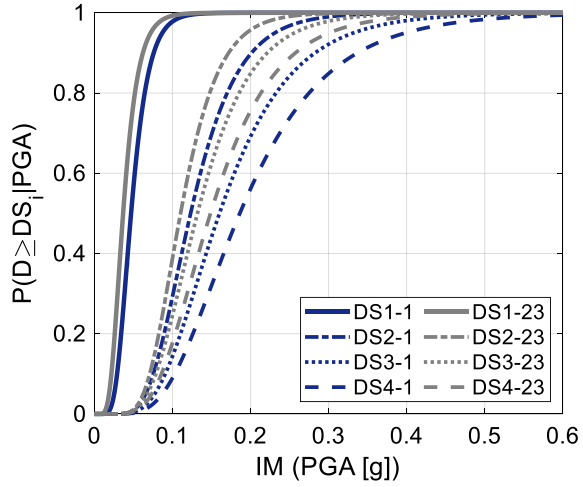

(a)

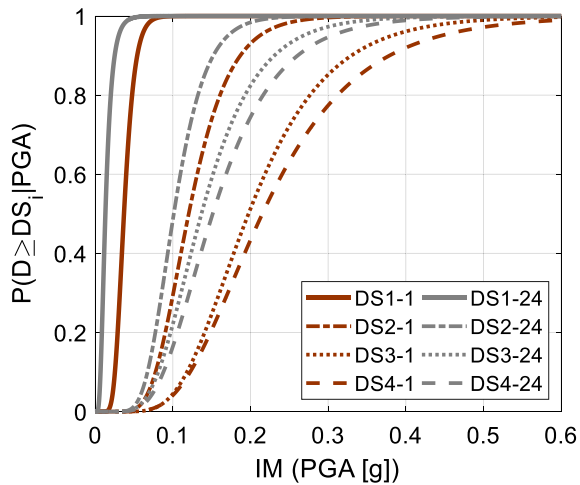

(c)

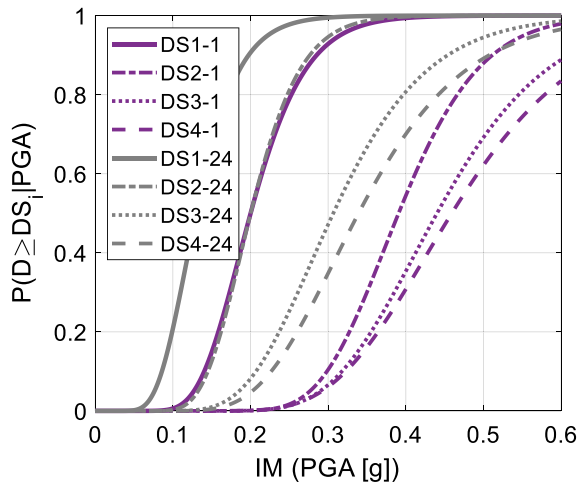

(e)

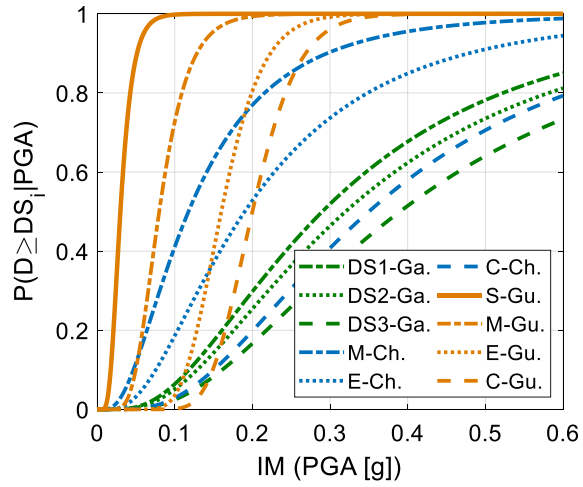

(b)

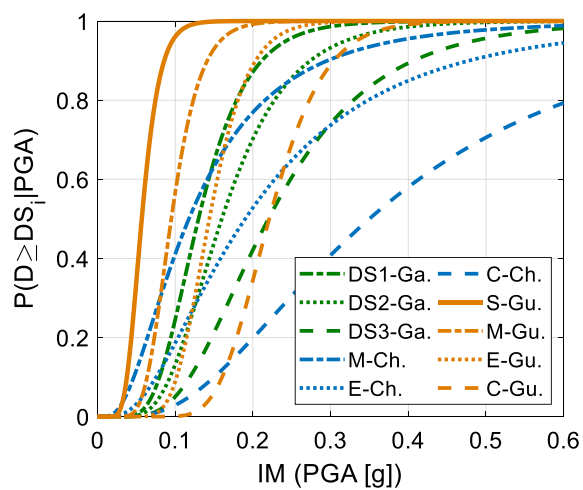

(d)

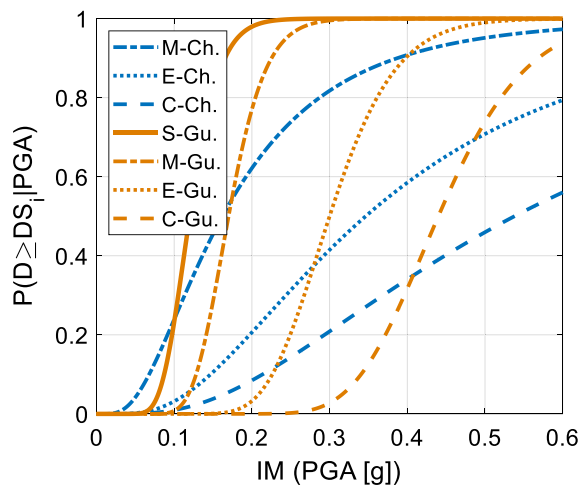

(f)

Fig. 8 Fragility curves for: a URM-SM1 and URM-SM23 school buildings, b URM-SM buildings from (Gautam et al. 2018) Ga., (Chaulagain et al. 2016) Ch. and (Guragain 2015) Gu., c URM-BM1 and URMBM24 school buildings, d URM-BM buildings from (Gautam et al. 2018) Ga., (Chaulagain et al. 2016) Ch. and (Guragain 2015) Gu., e URM-BC1 and URM-BC24 school buildings, f URM-BC buildings from (Gautam et al. 2018) Ga., (Chaulagain et al. 2016) Ch. and (Guragain 2015) Gu 
Table 5 Median values and dispersion for URM-SM schools and comparison with previous works

\begin{tabular}{|c|c|c|c|c|c|c|c|c|}
\hline & \multicolumn{2}{|c|}{ DS1-slight } & \multicolumn{2}{|c|}{ DS2-moderate } & \multicolumn{2}{|c|}{ DS3-extensive } & \multicolumn{2}{|c|}{ DS4-collapse } \\
\hline & $\eta$ & $\beta$ & $\eta$ & $\beta$ & $\eta$ & $\beta$ & $\eta$ & $\beta$ \\
\hline URM-SM1 & 0.047 & 0.37 & 0.12 & 0.38 & 0.16 & 0.44 & 0.18 & 0.46 \\
\hline URM-SM23 & 0.037 & 0.41 & 0.11 & 0.35 & 0.13 & 0.40 & 0.15 & 0.43 \\
\hline Gautam et al. (2018) & - & - & 0.29 & 0.70 & 0.32 & 0.71 & 0.39 & 0.69 \\
\hline Chaulagain et al. (2016) & - & - & 0.12 & 0.72 & 0.19 & 0.72 & 0.35 & 0.66 \\
\hline Guragain (2015) & 0.030 & 0.42 & 0.080 & 0.37 & 0.16 & 0.26 & 0.20 & 0.23 \\
\hline
\end{tabular}

Table 6 Median values and dispersion for URM-BM schools and comparison with previous works

\begin{tabular}{|c|c|c|c|c|c|c|c|c|}
\hline & \multicolumn{2}{|c|}{ DS1-slight } & \multicolumn{2}{|c|}{ DS2-moderate } & \multicolumn{2}{|c|}{ DS3-extensive } & \multicolumn{2}{|c|}{ DS4-collapse } \\
\hline & $\eta$ & $\beta$ & $\eta$ & $\beta$ & $\eta$ & $\beta$ & $\eta$ & $\beta$ \\
\hline URM-BM1 & 0.037 & 0.29 & 0.12 & 0.34 & 0.20 & 0.39 & 0.22 & 0.44 \\
\hline URM-BM24 & 0.013 & 0.50 & 0.10 & 0.32 & 0.14 & 0.41 & 0.15 & 0.43 \\
\hline Gautam et al. (2018) & - & - & 0.13 & 0.38 & 0.16 & 0.42 & 0.22 & 0.48 \\
\hline Chaulagain et al. (2016) & - & - & 0.12 & 0.72 & 0.19 & 0.72 & 0.35 & 0.66 \\
\hline Guragain (2015) & 0.057 & 0.32 & 0.095 & 0.31 & 0.14 & 0.27 & 0.22 & 0.25 \\
\hline
\end{tabular}

Table 7 Median values and dispersion for URM-BC schools and comparison with previous works

\begin{tabular}{|c|c|c|c|c|c|c|c|c|}
\hline & \multicolumn{2}{|c|}{ DS1-slight } & \multicolumn{2}{|c|}{ DS2-moderate } & \multicolumn{2}{|c|}{ DS3-extensive } & \multicolumn{2}{|c|}{ DS4-collapse } \\
\hline & $\eta$ & $\beta$ & $\eta$ & $\beta$ & $\eta$ & $\beta$ & $\eta$ & $\beta$ \\
\hline URM-BC1 & 0.20 & 0.27 & 0.39 & 0.21 & 0.44 & 0.25 & 0.46 & 0.27 \\
\hline URM-BC24 & 0.13 & 0.33 & 0.20 & 0.25 & 0.31 & 0.31 & 0.34 & 0.32 \\
\hline Chaulagain et al. (2016) & - & - & 0.16 & 0.68 & 0.35 & 0.67 & 0.55 & 0.72 \\
\hline Guragain (2015) & 0.12 & 0.25 & 0.17 & 0.22 & 0.30 & 0.22 & 0.44 & 0.20 \\
\hline
\end{tabular}

Table 8 Distribution of results with respect to governing failure mechanism. Not applicable failure mechanisms are indicated with a dash (-)

\begin{tabular}{|c|c|c|c|c|c|}
\hline & $\begin{array}{l}\text { OOP non-loadbear- } \\
\text { ing ground story [\%] }\end{array}$ & $\begin{array}{l}\text { OOP loadbearing } \\
\text { ground story [\%] }\end{array}$ & $\begin{array}{l}\text { OOP non-loadbear- } \\
\text { ing upper story [\%] }\end{array}$ & $\begin{array}{l}\text { OOP loadbearing } \\
\text { upper story [\%] }\end{array}$ & IP [\%] \\
\hline URM-SM1 & 48.7 & 51.3 & - & - & - \\
\hline URM-SM23 & 30.3 & 0.0 & 41.0 & 28.7 & - \\
\hline URM-BM1 & 49.8 & 50.2 & - & - & - \\
\hline URM-BM24 & 24.0 & 0.0 & 48.7 & 27.3 & - \\
\hline URM-BC1 & - & 63.5 & - & - & 36.5 \\
\hline URM-BC24 & - & 0.3 & - & 43.7 & 56 \\
\hline
\end{tabular}


than observational values. The comparison between URM-BM fragilities and the corresponding observational ones shows instead a better agreement. These results are in line with what is observed in other regional contexts (e.g. Rota et al. 2008; Borzi et al. 2008) where analytical fragilities are generally more conservative and with less dispersion. Usually these differences depend on two aspects: (i) analytical fragilities neglect the epistemic uncertainty of the model, (ii) in the context of developing countries, empirical relationships are usually derived from incomplete damage datasets and rather poor shake maps (McGowan et al. 2017).

- Comparison with fragility curves reported by Chaulagain et al. (2016)—Fragility curves reported by Chaulagain et al. (2016) are characterized by larger dispersion when compared with the analytical curves of this study. In terms of median PGAs there is a good agreement at DS2 (Moderate) and DS3 (Extensive) with one-story URM-SM/BM buildings. At DS4 (Collapse) $\eta$ result larger for any building typology. Given the lack of information on the methodology used to derive these curves, it is not possible to draw any conclusion about the source of the discrepancies.

- Comparison with analytical fragility curves by Guragain (2015)—For any structural type, median PGAs by Guragain (2015) appear in good agreement with the analytical results of this study. Dispersion vales are generally lower, probably due to the limited number of GMs adopted by Guragain (2015) to account for record-to-record variability.

\section{Conclusions}

In this work an analysis of the available data on the Nepalese school building stock has been produced by comparing statistics from different sources and geographical areas. Fragility curves for Nepali unreinforced masonry (URM) school typologies have been derived adopting a spectral-based methodology that accounts for in-plane/out-of-plane damage potential in a single easy-to-use analytical framework. Particularly, a recent closed-form solution for out-of-plane assessment has been integrated (Giordano et al. 2020a) with an existing approach for in-plane damage evaluation. Three URM structural types have been considered, namely, stone in mud (URM-SM), brick in mud (URM$\mathrm{BM}$ ), and brick in cement (URM-BC). The analyses have been carried out for singlestory and multi-story building classes to increase the granularity of the fragility model. Inter-building, intra-building and record-to-record variabilities have been accounted in the analysis.

The analytical results have been compared with Nepal-specific fragility studies available in the literature. The new fragilities show a good agreement with respect to the analytical study by Guragain (2015). On the contrary, the comparison with observational fragilities (Gautam et al. 2018) shows larger discrepancies since: (i) the analytical results do not account for the epistemic uncertainty of the model and (ii) in the context of Nepal, empirical relationships are negatively affected by low-quality of damage data and poor shake maps. This study underlines that more experimental research on traditional Nepali masonry is needed to release some of the assumptions of the model. By adoptiong the same methodology, the present results can be easily updated when additional country-specific data become available. The new set of fragility curves, in combination with the existing studies, increases our understanding of the vulnerability 
of Nepali masonry schools and can be used for seismic loss assessment at building and portfolio scale.

Acknowledgements This work was funded by the UK Global Challenges Research Fund - Engineering and Physical Science Research Council (GCRF-EPSRC) under the project "Seismic Safety and Resilience of Schools in Nepal" SAFER (EP/P028926/1), https://www.safernepal.net. The underlying data for this study were drawn from the referenced literature. All the data produced in this work are provided in full within this paper.

Open Access This article is licensed under a Creative Commons Attribution 4.0 International License, which permits use, sharing, adaptation, distribution and reproduction in any medium or format, as long as you give appropriate credit to the original author(s) and the source, provide a link to the Creative Commons licence, and indicate if changes were made. The images or other third party material in this article are included in the article's Creative Commons licence, unless indicated otherwise in a credit line to the material. If material is not included in the article's Creative Commons licence and your intended use is not permitted by statutory regulation or exceeds the permitted use, you will need to obtain permission directly from the copyright holder. To view a copy of this licence, visit http://creativecommons.org/licenses/by/4.0/.

\section{References}

Adhikari R, D’Ayala D (2019) Applied element modelling and pushover analysis of unreinforced masonry buildings with flexible roof diaphragm. In: Proceedings of the 7th ECCOMAS thematic conference on computational methods in structural dynamics and earthquake engineering. Crete, Greece.

Ahmad N, Ali Q, Adil M, Khan AN (2018) Developing seismic risk prediction functions for structures. Shock Vib 2018:1-22. https://doi.org/10.1155/2018/4186015

Ahmad N, Ali Q, Crowley H, Pinho R (2014) Earthquake loss estimation of residential buildings in Pakistan. Nat Hazards 73:1889-1955. https://doi.org/10.1007/s11069-014-1174-8

Aon Benfield (2015) 2015 Nepal Earthquake event recap report. London

ARUP (2015) Global program for safer schools: structural typologies. London

ASCE/SEI (2010) ASCE/SEI 7-10 minimum design loads for buildings and other structures

Asian Development Bank (2014) Strategy and plan for increasing disaster resilience for schools in Nepal. Bangkok

Aspinall W (2010) A route to more tractable expert advice. Nature 463:294-295. https://doi. org/10.1038/463294a

Benedetti D, Carydis P, Pezzoli P (1998) Shaking table tests on 24 simple masonry buildings. Earthq Eng Struct Dyn 27:67-90. https://doi.org/10.1002/(SICI)1096-9845(199801)27:1\%3c67::AID-EQE71 $9 \% 3 \mathrm{e} 3.0 . \mathrm{CO} ; 2-\mathrm{K}$

Bommer JJ, Acevedo AB (2004) The use of real earthquake accelerograms as input to dynamic analysis. J Earthq Eng 8:43-91. https://doi.org/10.1080/13632460409350521

Borzi B, Crowley H, Pinho R (2008) Simplified pushover-based earthquake loss assessment (SP-BELA) method for masonry buildings. Int J Archit Herit 2:353-376. https://doi.org/10.1080/1558305070 1828178

Brando G, Rapone D, Spacone E et al (2017) Damage reconnaissance of unreinforced masonry bearing wall buildings after the 2015 Gorkha, Nepal, Earthquake. Earthq Spectra 33:S243-S273. https://doi. org/10.1193/010817EQS009M

Brencich A, de Felice G (2009) Brickwork under eccentric compression: experimental results and macroscopic models. Constr Build Mater 23:1935-1946. https://doi.org/10.1016/j.conbuildmat.2008.09.004

Build Change (2015) April 25, 2015: Gorkha earthquake, Nepal: post-disaster reconnaissance report. Denver

Bureau of Indian Standards (1974) Specifications 91-92 (7): stone work. New Delhi

Bureau of Indian Standards (1987) IS 875: code of practice for design loads (other than earthquake) for buildings and structures. New Delhi

Byrne MD (2013) How many times should a stochastic model be run? An approach based on confidence intervals. In: Proceedings of the 12th international conference cognation model

Calvi GM, Pinho R, Magenes G et al (2006) Development of seismic vulnerability assessment methodologies over the past 30 years. ISET J 43:75-104. https://doi.org/10.1109/JSTQE.2007.897175 
Calvi PM, Sullivan TJ (2014) Estimating floor spectra in multiple degree of freedom systems. Earthq Struct 7:17-38. https://doi.org/10.12989/eas.2014.7.1.017

Cavaleri L, Failla A, La Mendola L, Papia M (2005) Experimental and analytical response of masonry elements under eccentric vertical loads. Eng Struct 27:1175-1184. https://doi.org/10.1016/j.engst ruct.2005.02.012

Ceran HB, Erberik MA (2013) Effect of out-of-plane behavior on seismic fragility of masonry buildings in Turkey. Bull Earthq Eng 11:1775-1795. https://doi.org/10.1007/s10518-013-9449-0

Chaulagain H, Rodrigues H, Silva V et al (2016) Earthquake loss estimation for the Kathmandu Valley. Bull Earthq Eng 14:59-88. https://doi.org/10.1007/s10518-015-9811-5

Chiaro G, Kiyota T, Pokhrel RM et al (2015) Reconnaissance report on geotechnical and structural damage caused by the 2015 Gorkha Earthquake. Nepal Soils Found 55:1030-1043. https://doi.org/10.1016/j. sandf.2015.09.006

D’Ayala D, Speranza E (2003) Definition of collapse mechanisms and seismic vulnerability of historic masonry buildings. Earthq Spectra 19:479-509. https://doi.org/10.1193/1.1599896

D'Ayala DF, Paganoni S (2011) Assessment and analysis of damage in L'Aquila historic city centre after 6th April 2009. Bull Earthq Eng 9:81-104. https://doi.org/10.1007/s10518-010-9224-4

D’Ayala D, Meslemn A, Vamvatsikos D, Porter K, Rossetto T, Silva V (2015) Guidelines for analytical vulnerability assessment of low/mid-rise buildings, gem vulnerability global component project. doi: https ://doi.org/10.13117/GEM.VULN-MOD.TR2014.12

de Felice G (2011) Out-of-plane seismic capacity of masonry depending on wall section morphology. Int J Archit Herit 5:466-482. https://doi.org/10.1080/15583058.2010.530339

De Risi R, Goda K, Mori N, Yasuda T (2017) Bayesian tsunami fragility modeling considering input data uncertainty. Stoch Environ Res Risk Assess 31:1253-1269. https://doi.org/10.1007/s00477-016-1230-X

Degli Abbati S, Lagomarsino S (2017) Out-of-plane static and dynamic response of masonry panels. Eng Struct 150:803-820. https://doi.org/10.1016/j.engstruct.2017.07.070

Dimitrakopoulos EG, Paraskeva TS (2015) Dimensionless fragility curves for rocking response to near-fault excitations. Earthq Eng Struct Dyn 44:2015-2033. https://doi.org/10.1002/eqe.2571

Doherty K, Griffith MC, Lam N, Wilson J (2002) Displacement-based seismic analysis for out-of-plane bending of unreinforced masonry walls. Earthq Eng Struct Dyn 31:833-850. https://doi.org/10.1002/ eqe. 126

EERI (2016) M7.8 Gorkha, Nepal Earthquake on April 25, 2015 and its Aftershocks. Earthquake Engineering Research Institute, Oakland

EERI (2019) Learning from earthquakes reconnaissance archive. Earthquake Engineering Research Institute, Oakland

European Commitee for Standardization (2004) Eurocode 8: design of structures for earthquake resistance Part 1: general rules, seismic actions and rules for buildings. Eur Comm Stand 1:231

Fajfar P (2000) A nonlinear analysis method for performance-based seismic design. Earthq Spectra 16:573592. https://doi.org/10.1193/1.1586128

Ferreira TM, Costa AA, Arede A et al (2015) Experimental characterization of the out-of-plane performance of regular stone masonry walls, including test setups and axial load influence. Bull Earthq Eng 13:2667-2692. https://doi.org/10.1007/s10518-015-9742-1

Frankie TM, Gencturk B, Elnashai AS (2012) Simulation-based fragility relationships for unreinforced masonry buildings. J Struct Eng 139:485. https://doi.org/10.1061/(ASCE)ST.1943-541X.0000648

Freeman SA (1978) Prediction of response of concrete buildings to severe earthquake motion. ACI J 55:589-606. https://doi.org/10.14359/6629

Gautam D, Chaulagain H (2016) Structural performance and associated lessons to be learned from world earthquakes in Nepal after 25 April 2015 (MW 7.8) Gorkha earthquake. Eng Fail Anal 68:222-243. https://doi.org/10.1016/j.engfailanal.2016.06.002

Gautam D, Fabbrocino G, Santucci de Magistris F (2018) Derive empirical fragility functions for Nepali residential buildings. Eng Struct 171:617-628. https://doi.org/10.1016/j.engstruct.2018.06.018

Gautam D, Rodrigues H, Bhetwal KK et al (2016) Common structural and construction deficiencies of Nepalese buildings. Innov Infrastruct Solut 1:1. https://doi.org/10.1007/s41062-016-0001-3

Gentile R, Galasso C (2019) From rapid visual survey to multi-hazard risk prioritisation and numerical fragility of school buildings in Banda Aceh, Indonesia. Nat Hazards Earth Syst Sci Discuss 1-31:1365-1386

Giaretton M, Valluzzi MR, Mazzon N, Modena C (2017) Out-of-plane shake-table tests of strengthened multi-leaf stone masonry walls. Bull Earthq Eng 15:4299-4317. https://doi.org/10.1007/s1051 8-017-0125-7 
Giordano N, Crespi P, Franchi A (2017) Flexural strength-ductility assessment of unreinforced masonry cross-sections: analytical expressions. Eng Struct 148:399-409. https://doi.org/10.1016/j.engst ruct.2017.06.047

Giordano N, De Luca F, Maskey PN, Sextos A (2019a) Sensitivity of out-of-plane capacity to input parameters of Nepali URM walls In: XVIII ANIDIS conference of seismic engineering, Ascoli Piceno, Italy.

Giordano N, De Luca F, Sextos A, Maskey PN (2019b) Derivation of fragility curves for URM school buildings in Nepal. In: Proceedings of the 13th international conference on applications of statistics and probability in civil engineering, ICASP13. Seoul, South Korea, pp 1-8.

Giordano N, De Luca F, Sextos A (2020a) Out-of-plane closed-form solution for the seismic assessment of unreinforced masonry schools in Nepal. Eng Struct 203:109548. https://doi.org/10.1016/j.engst ruct.2019.109548

Giordano N, Mosalam KM, Günay S (2020b) Probabilistic performance-based seismic assessment of an existing masonry building. Earthq Spectra 36(1):271-298. https://doi.org/10.1177/8755293019878191

Giordano N, De Luca F, Sextos A et al (2020c) Empirical seismic fragility models for Nepalese school buildings. Nat Hazards. https://doi.org/10.1007/s11069-020-04312-1

Giresini L, Casapulla C, Denysiuk R et al (2018) Fragility curves for free and restrained rocking masonry façades in one-sided motion. Eng Struct 164:195-213. https://doi.org/10.1016/j.engstruct.2018.03.003

Government of Nepal (2015) Nepal Earthquake 2015: post disaster needs assessment. Kathmandu

Griffith MC, Lam NTK, Wilson JL, Doherty K (2004) Experimental investigation of unreinforced brick masonry walls in flexure. J Struct Eng 130:423-432. https://doi.org/10.1061/ (ASCE)0733-9445(2004)130:3(423)

Grünthal G (1998) European macroseismic scale 1998 EMS-98. European Center for Geodynamics and Seismology, Luxembourg

Guragain R (2015) Development of earthquake risk assessment system for Nepal. University of Tokyo

Hancilar U, Sesetyan K, Cakti E (2020) Comparative earthquake loss estimations for high-code buildings in Istanbul. Soil Dyn Earthq Eng 129:105956. https://doi.org/10.1016/j.soildyn.2019.105956

Jaiswal K, Wald D, D'Ayala D (2011) Developing empirical collapse fragility functions for global building types. Earthq Spectra 27:775-795. https://doi.org/10.1193/1.3606398

Javed M, Magenes G, Alam B et al (2015) Experimental seismic performance evaluation of unreinforced brick masonry shear walls. Earthq Spectra 31:215-246. https://doi.org/10.1193/111512EQS329M

JCSS (2011) Probabilistic model code_-Part 3: resistance models-3.2 Masonry Properties

JCSS (2001) Probabilistic model code—Part 2: load models

Lagomarsino S (2015) Seismic assessment of rocking masonry structures. Bull Earthq Eng 13:97-128. https ://doi.org/10.1007/s10518-014-9609-x

Lagomarsino S, Cattari S (2015) PERPETUATE guidelines for seismic performance-based assessment of cultural heritage masonry structures. Bull Earthq Eng 13:13-47. https://doi.org/10.1007/s1051 8-014-9674-1

Lagomarsino S, Giovinazzi S (2006) Macroseismic and mechanical models for the vulnerability and damage assessment of current buildings. Bull Earthq Eng 4:415-443. https://doi.org/10.1007/s1051 8-006-9024-z

Malhotra PK (2006) Smooth spectra of horizontal and vertical ground motions. Bull Seismol Soc Am 96:506-518. https://doi.org/10.1785/0120050062

Malomo D, Pinho R, Penna A (2018) Using the applied element method for modelling calcium silicate brick masonry subjected to in-plane cyclic loading. Earthq Eng Struct Dyn 47:1610-1630. https://doi. org/10.1002/eqe.3032

McGowan SM, Jaiswal KS, Wald DJ (2017) Using structural damage statistics to derive macroseismic intensity within the Kathmandu valley for the 2015 M7.8 Gorkha. Nepal earthquake Tectonophysics 714-715:158-172. https://doi.org/10.1016/j.tecto.2016.08.002

Muzzini E, Aparicio G (2013) Urban growth and spatial transition in Nepal. World Bank, Washington, DC

NSET (2000) Seismic vulnerability of the public school buildings of Kathmandu Valley and methods for reducing it. In: National Society for Earthquake Technology, Kathmandu, Nepal

Paci-Green R, Pandley B, Friedman R (2015) Post-earthquake comparative assessment of school reconstruction and social impacts in Nepal. USA

Parisi F, Sabella G, Augenti N (2016) Constitutive model selection for unreinforced masonry cross sections based on best-fit analytical moment-curvature diagrams. Eng Struct 111:451-466. https://doi. org/10.1016/j.engstruct.2015.12.036

Park J, Towashiraporn P, Craig JI, Goodno BJ (2009) Seismic fragility analysis of low-rise unreinforced masonry structures. Eng Struct 31:125-137. https://doi.org/10.1016/j.engstruct.2008.07.021

Rits-DMUCH (2012) Disaster risk management for the historic city of Patan, Nepal. Research Center for Disaster Mitigation of Urban Cultural Heritage, Kyoto, Japan 
Robinson TR, Rosser NJ, Densmore AL et al (2018) Use of scenario ensembles for deriving seismic risk. Proc Natl Acad Sci 115:E9532-E9541. https://doi.org/10.1073/pnas.1807433115

Rossetto T, Gehl P, Minas S et al (2016) FRACAS: a capacity spectrum approach for seismic fragility assessment including record-to-record variability. Eng Struct 125:337-348. https://doi.org/10.1016/j. engstruct.2016.06.043

Rota M, Penna A, Strobbia CL (2008) Processing Italian damage data to derive typological fragility curves. Soil Dyn Earthq Eng 28:933-947. https://doi.org/10.1016/j.soildyn.2007.10.010

Rota M, Penna A, Magenes G (2010) A methodology for deriving analytical fragility curves for masonry buildings based on stochastic nonlinear analyses. Eng Struct 32:1312-1323. https://doi.org/10.1016/j. engstruct.2010.01.009

Sajid HU, Ashraf M, Ali Q, Sajid SH (2018) Effects of vertical stresses and flanges on seismic behavior of unreinforced brick masonry. Eng Struct 155:394-409. https://doi.org/10.1016/j.engstruct.2017.11.013

Sextos A, Mason C (2018) Seismic Safety and Resilience of Schools in Nepal (SAFER): technical manual and user's guide. University of Bristol, UK. www.safernepal.net.

Shahzada K, Khan AN, Elnashai AS et al (2012) Experimental seismic performance evaluation of unreinforced brick masonry buildings. Earthq Spectra 28:1269-1290. https://doi.org/10.1193/1.4000073

Sharma K, Deng L, Noguez CC (2016) Field investigation on the performance of building structures during the April 25, 2015, Gorkha earthquake in Nepal. Eng Struct 121:61-74. https://doi.org/10.1016/j.engst ruct.2016.04.043

Shawa O, de Felice G, Mauro A, Sorrentino L (2012) Out-of-plane seismic behaviour of rocking masonry walls. Earthq Eng Struct Dyn 41:949-968. https://doi.org/10.1002/eqe.1168

Shinozuka M, Feng MQ, Kim H-K, Kim S (2000) Nonlinear static procedure for fragility curve development. J Eng Mech 126:1287-1295. https://doi.org/10.1061/(ASCE)0733-9399(2000)126:12(1287)

Silva V, Akkar S, Baker J et al (2019) Current challenges and future trends in analytical fragility and vulnerability modelling. Earthq Spectra. https://doi.org/10.1193/042418EQS101O

Simoes A, Milosevic J, Meireles H et al (2015) Fragility curves for old masonry building types in Lisbon. Bull Earthq Eng 13:3083-3105. https://doi.org/10.1007/s10518-015-9750-1

Smerzini C, Galasso C, Iervolino I, Paolucci R (2014) Ground motion record selection based on broadband spectral compatibility. Earthq Spectra 30:1427-1448. https://doi.org/10.1193/052312EQS197M

Suarez LE, Singh MP (1987) Floor response spectra with structure-equipment interaction effects by a mode synthesis approach. Earthq Eng Struct Dyn 15:141-158

United Nations Department of Economic and Social Affairs Population Division (2018) World urbanization prospects: the 2018 revision, Online Edition

United Nations Office for Disaster Risk Reduction (2017) Comprehensive school safety: a global framework in support of The Global Alliance for Disaster Risk Reduction and Resilience in the Education Sector and The Worldwide Initiative for Safe Schools

Vaculik J, Griffith M (2017) Out-of-plane load-displacement model for two-way spanning masonry walls. Eng Struct 141:328-343. https://doi.org/10.1016/j.engstruct.2017.03.024

Wang M, Liu K, Lu H et al (2018) In-plane cyclic tests of seismic retrofits of rubble-stone masonry walls. Bull Earthq Eng 16:1941-1959. https://doi.org/10.1007/s10518-017-0262-z

World Bank (2017) Global program for safer schools. Washington, DC. gpss.worldbank.org.

World Bank (2019a) Global program for safer schools: catalog of building types (rubble stone masonry in mud mortar index building). Washington, DC. https://gpss.worldbank.org/sites/gpss/files/2019-06/ IB3_LBM_UCM-URM2_LR_PD.pdf.

World Bank (2019b) Global program for safer schools: global library of school infrastructure. Washington, DC. https://gpss.worldbank.org/en/glosi/about-glosi

Yepes-Estrada C, Silva V, Rossetto T et al (2016) The global earthquake model physical vulnerability database. Earthq Spectra 32:2567-2585. https://doi.org/10.1193/011816EQS015DP

Publisher's Note Springer Nature remains neutral with regard to jurisdictional claims in published maps and institutional affiliations. 